Thaker B, Limbachiya N, Patel K and Patel N (2017) Calamitic liquid crystals involving fused ring and their metallomesogens. Emerging Materials Research 6(2): 331-347 https://doi.org/10.1680/jemmr.15.00060
Emerging Materials Research Volume 6 Issue EMR2 Optical materials research article Received 06/10/2015 Accepted 30/05/2017 Published online 18/08/2017

Keywords: condensed matter/displays/liquid crystal display

\title{
Calamitic liquid crystals involving fused ring and their metallomesogens
}

1 Bharat Thaker PhD*

Director, Vidhyadeep Institute of Science, Surat, India

2 Nilesh Limbachiya PhD

Assistant Professor, J. N. M. Patel Science College, Surat, India

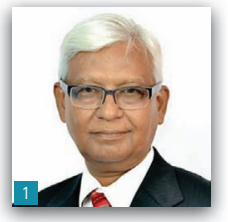

3 Kalpesh Patel MSc

Research scholar, Department of Chemistry, Veer Narmad South Gujarat University, Surat, India

4 Neeraj Patel PhD

QC Chemist, Gujarat Narmada Valley Fertilizers Company, Bharuch, India

In this paper, the authors report two different types of terminally substituted homologous series with an ester-azo central linkage involving fused-ring achiral liquid crystals such as 4-((4-chlorophenyl)diazenyl)-3-hydroxyphenyl 6-alkoxy-2naphthoate (series A) and 4-((4-nitrophenyl)diazenyl)-3-hydroxyphenyl 6-alkoxy-2-naphthoate (series B). Their copper (II) metallomesogens were synthesised and characterised by methods such as elemental analysis, Fourier transform infrared, proton $\left({ }^{1} \mathrm{H}\right)$ nuclear magnetic resonance (NMR), carbon-13 $\left({ }^{13} \mathrm{C}\right)$ NMR and mass spectroscopic studies. Thermotropic properties were studied by performing polarising optical microscopy and DSC analysis. All liquid crystalline compounds (ligands) display nematic and/or smectic phase/s. Unlike ligands, both types of copper (II) complexes show a solely nematic behaviour. The series $B$ exhibit Sm-form from $C_{7}$ derivatives where as series $A$ exhibit Sm-form from $C_{8}$ derivatives. The series $B$ is more thermally stable than series $A$. The series $A$ exhibit monotropic nematic phase for $C_{4}$ derivative and monotropic smectic phase for $C_{10}$ derivative. Whereas series $B$ display monotropic nematic phase for $C_{5}$ derivative and $C_{12}$ derive is fully monotropic i.e. both nematic and smectic phase obtained only on cooling cycle.

\section{Introduction}

Liquid crystals (LCs) are a fascinating phase of matter because of their orientational order with fluidity and optical anisotropy. A number of organic molecules and organic polymers that have delocalised $\pi$-electron systems are being extensively studied for applications in the field of non-linear optics. ${ }^{1-5}$

Azo dye LCs have attracted much attention for their potential uses in optical storage applications because of their easy availability, reasonable photofatigue resistance and the marked transformation of their molecular shape upon $\mathrm{E}$ to $\mathrm{Z}$ photoisomerisation. ${ }^{6-11}$ They have a reasonable dichroic ratio for reflective LC devices, which are of considerable interest owing to their low power consumption. ${ }^{12}$

Studies of dichroic dyes are attracting much attention due to the development of reflection-type guest-host LC displays. Azo dyes have been proposed as positive dichroic dyes for use in displays. ${ }^{13-15}$ The improvement in the solubility and dichroism of dyes is a challenging subject.

The structure/mesomorphic property relationship is the most attractive area of study for chemists in LC research, and a number of papers and monographs regarding this subject have been reported in the literature. ${ }^{16,17}$ Nevertheless, the vast range of synthetic possibilities in organic chemistry means that a variety of structures remain relatively unstudied. Within the classic calamitic structure, some functional groups have proven to be very useful in promoting mesomorphic properties. Generally, the ester group or azo group or ester-azo groups have been most commonly used as central bridging units and have been incorporated in many lowtemperature systems. In addition, the introduction of aromatic groups such as biphenyl or naphthyl has been widely studied because they give rise to a very stable mesophase and allow the introduction of substituents into different positions, leading to modification of the LC properties. ${ }^{18,19}$

Metallomesogens have attracted increasing attention due to the possibility of combining the physico-chemical properties contributed by the metal with those of organic framework. ${ }^{20-22}$ However, the understanding and control of phase behaviour are functions of molecular chain length, the nature of the substituents on the ligands, the spacer groups and metal ions. Among the first-row transition metals, metallomesogens with copper (II), exhibiting various smectic, nematic as columnar LC phases, have been prepared and studied. ${ }^{23,24}$ 
Due to the paramagnetism induced by the copper (Cu) (II) centre, these metallomesogens show interesting chemical and physical properties that can lead to potential applications. ${ }^{25-30}$

In order to evaluate the practical advantages of incorporating the fused-ring naphthalene system in the structure of liquid crystalline materials, the authors report in this paper two homologous series and a study of the mesomorphic properties of the 2,6-naphthyl benzoate terminal core. With this purpose in mind, this study was focused on two series of 2,6-naphthyl benzoate with an ester-azo linking group and chloro and nitro terminal groups and their copper (II) metallomesogens.

\section{Experimental}

\subsection{Materials}

For the synthesis of compounds of the homologous series (ligands) and their copper (II) complexes, the following materials were used. Alkyl bromide (Lancaster, England), 4-chloroaniline, 4-nitroaniline, resorcinol, 6-hydroxy-2-naphthoic acid was obtained from H.L. Chemical \& Engineer Pvt. Ltd, Maroli (Surat); $N, N^{\prime}$-dimethylaminopyridine was purchased from Merck (Germany); and copper (II) chloride dihydrate $\left(\mathrm{CuCl}_{2} \cdot 2 \mathrm{H}_{2} \mathrm{O}\right)$ and dicyclohexylcarbodiimide were acquired from Fluka Chemie (Switzerland). Anhydrous potassium carbonate, acetone, ethanol, methanol, acetic acid, ethyl acetate, dichloromethane, pyridine, petroleum ether, diethyl ether, dimethylformamide, phosphoryl chloride $\left(\mathrm{POCl}_{3}\right)$, hydrochloric acid $(\mathrm{HCl})$, sulfuric acid $\left(\mathrm{H}_{2} \mathrm{SO}_{4}\right)$, ammonia and so on were used as received. Column chromatography was performed on an Acme silica gel (100-200 mesh). The solvents were dried and distilled prior to use.

\subsection{Synthesis}

The synthetic route for the preparation of series A, B, MC and MD compounds is illustrated in the following section.

\subsubsection{Synthesis of 6-alkoxy-2-naphthoic acid}

6-Hydroxy-2-naphthoic acid $(2.5 \mathrm{~g}, 13 \mathrm{mmol})$ and potassium hydroxide $(\mathrm{KOH})(1.46 \mathrm{~g}, 26 \mathrm{mmol})$ were dissolved in ethanol/

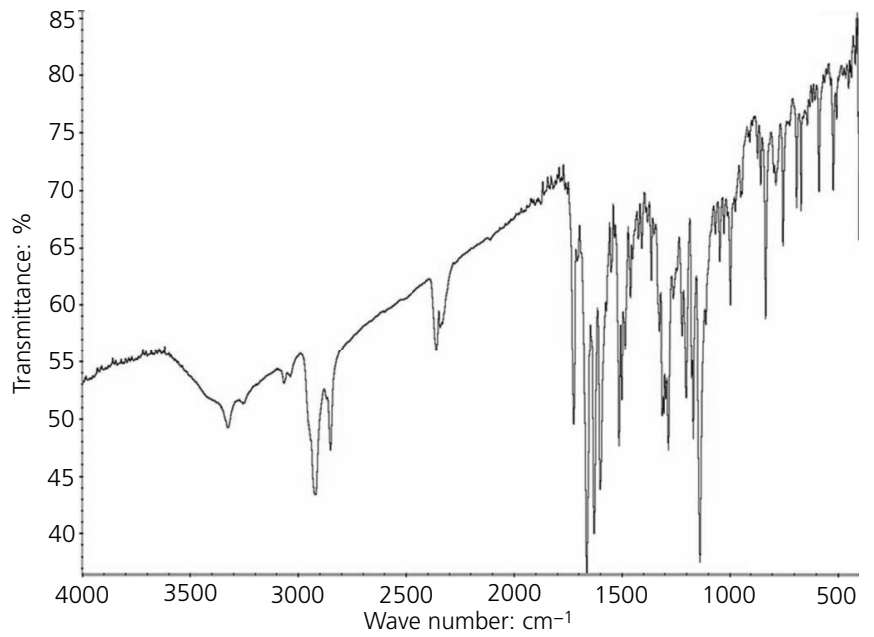

(a)

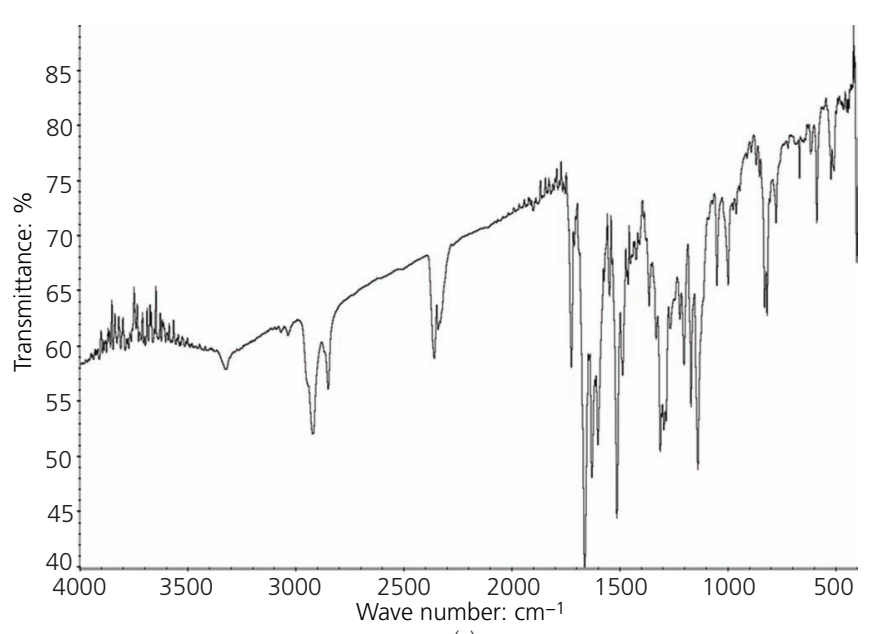

(c)

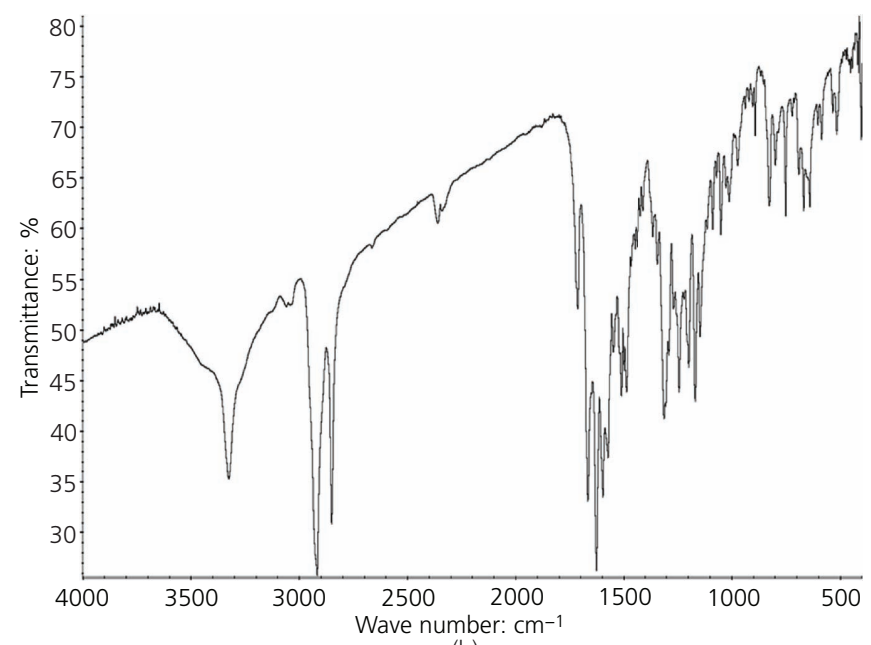

(b)

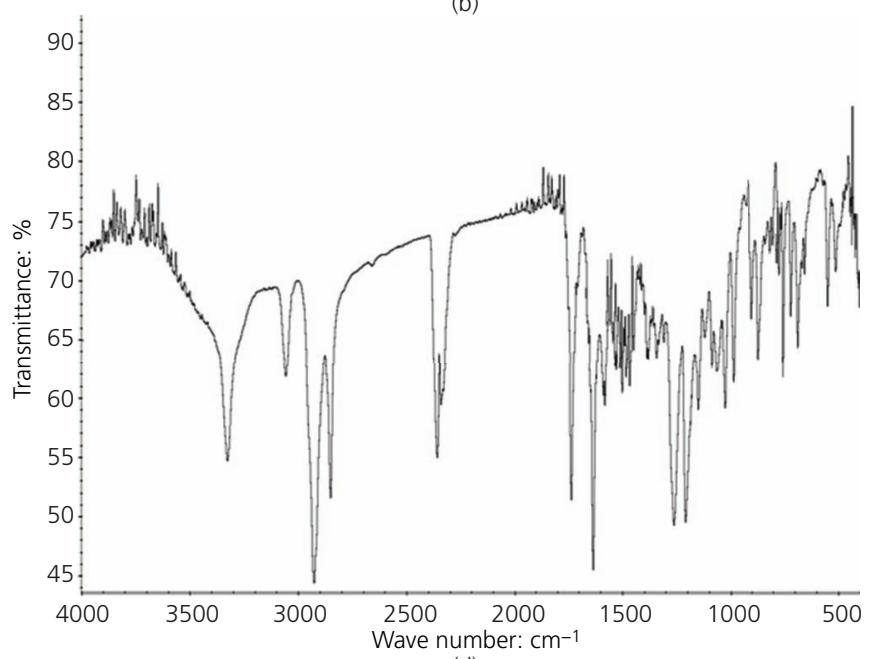

Figure 1. FT-IR spectra of compounds (a) $A_{8}$, (b) $A_{16}$, (c) $B_{8}$ and (d) $B_{16}$ 
water $(100 \mathrm{ml}, 9: 1)$, and the solution was stirred for $20 \mathrm{~min}$. $n$ Alkyl bromide $(32.5 \mathrm{mmol})$ was then added, and the mixture was heated under reflux for $24 \mathrm{~h}$. When the reaction was completed, potassium hydroxide $(0.73 \mathrm{~g}, 13 \mathrm{mmol})$ was added, and the mixture was heated under reflux for an additional $4 \mathrm{~h}$. The ethanol was evaporated, and the mixture was poured into water and acidified to approximately $\mathrm{pH}=2-3$ with acetic acid. The precipitate was filtered and washed with water and ether and then recrystallised twice from glacial acetic acid to yield $71-80 \%$ concentrations. The synthetic route has also been described in the literature. ${ }^{31,32}$

\subsubsection{Synthesis of 4-chloro-2', $4^{\prime}$-dihydroxy azobenzene and 4-nitro-2', $4^{\prime}$-dihydroxy azobenzene}

A well-stirred mixture of 4-chloroaniline $(1.28 \mathrm{~g}, 0.01 \mathrm{~mol})$ and $40 \mathrm{ml}$ of 1:1 concentrated hydrochloric acid was cooled below $5^{\circ} \mathrm{C}$ and a solution of sodium nitrite $\left(\mathrm{NaNO}_{2}\right)(0 \cdot 76 \mathrm{~g}, 0.011 \mathrm{~mol})$ in water $(20 \mathrm{ml})$ was added dropwise in such a way that the
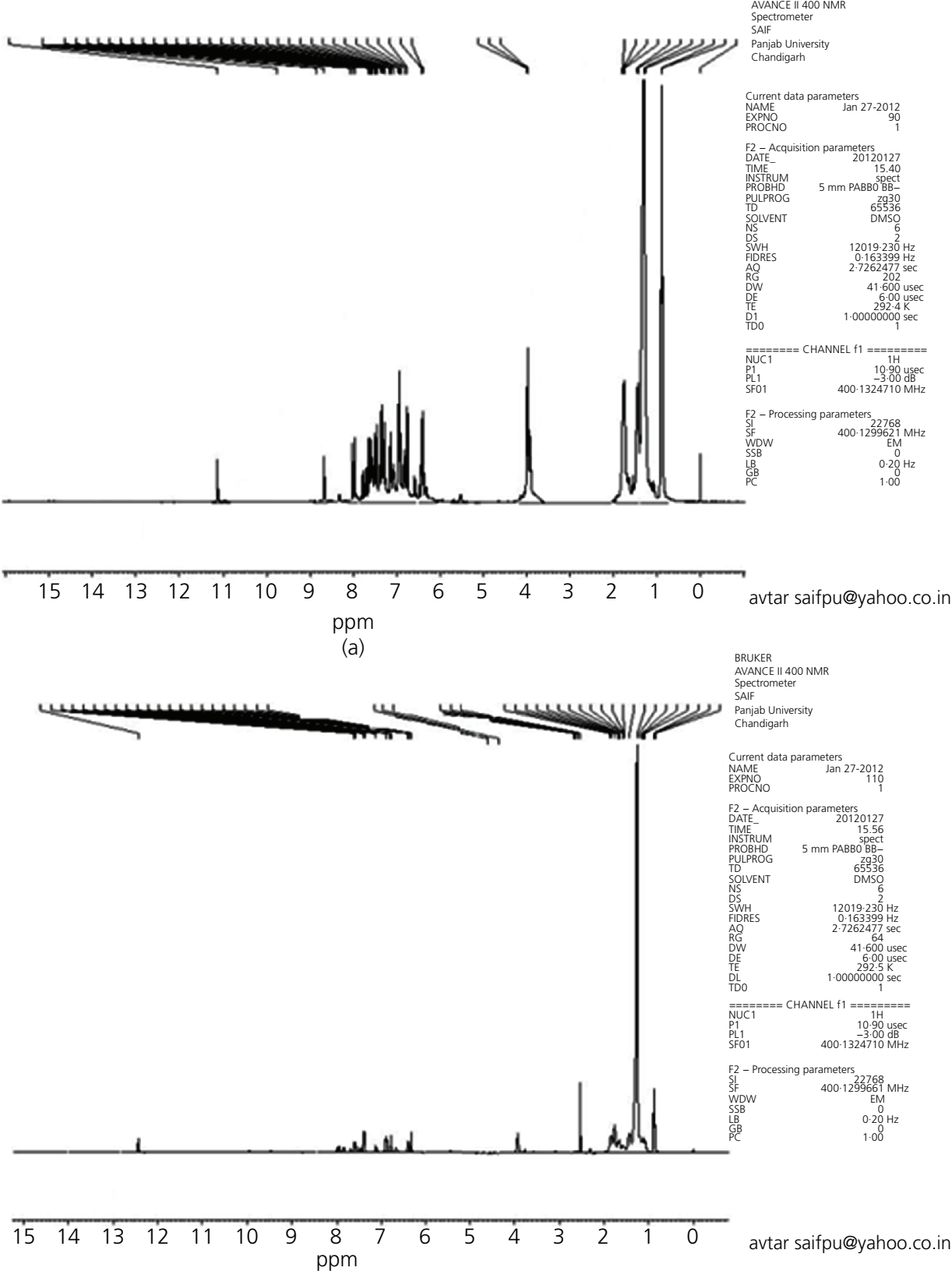

(b)

Figure 2. Proton NMR spectra of compounds (a) $A_{8}$, (b) $A_{16}$, (c) $B_{8}$ and (d) $B_{16}$ (continued on next page) 


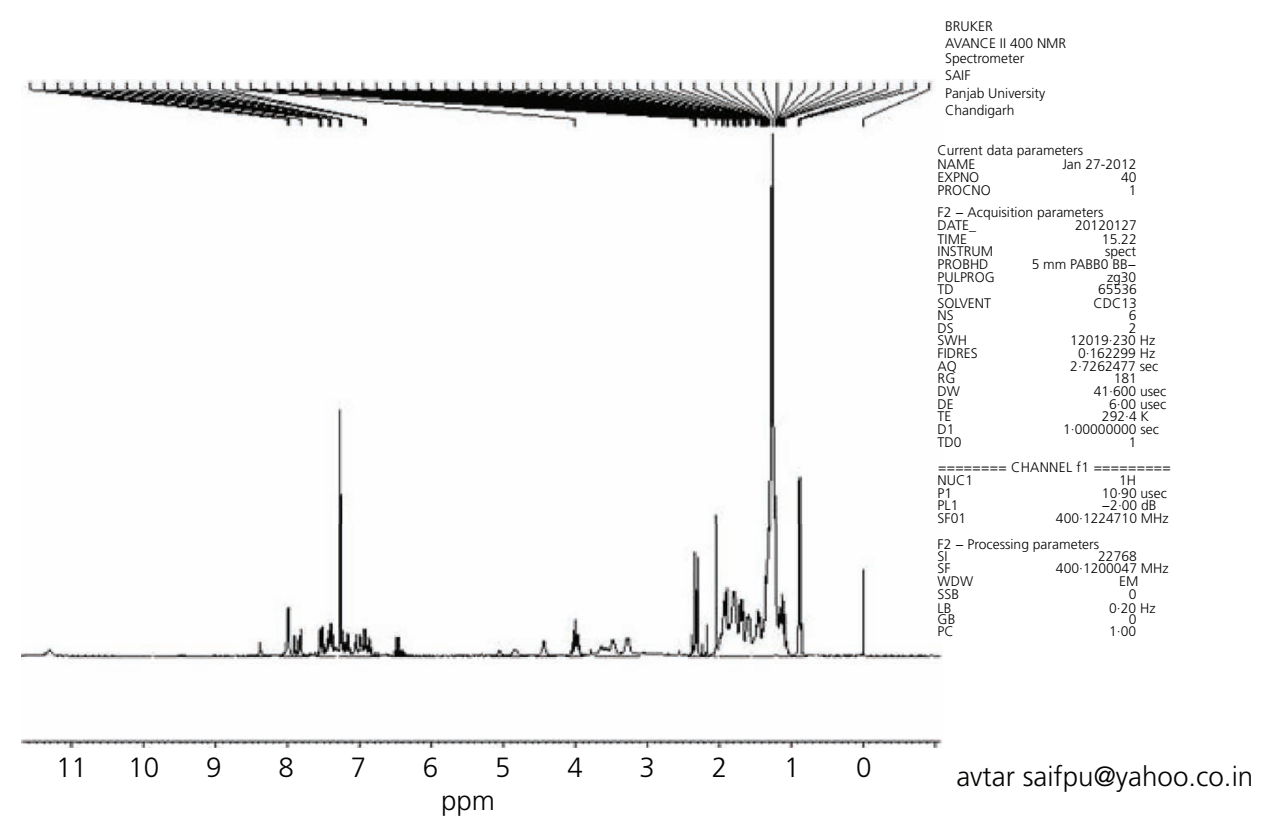

(c)
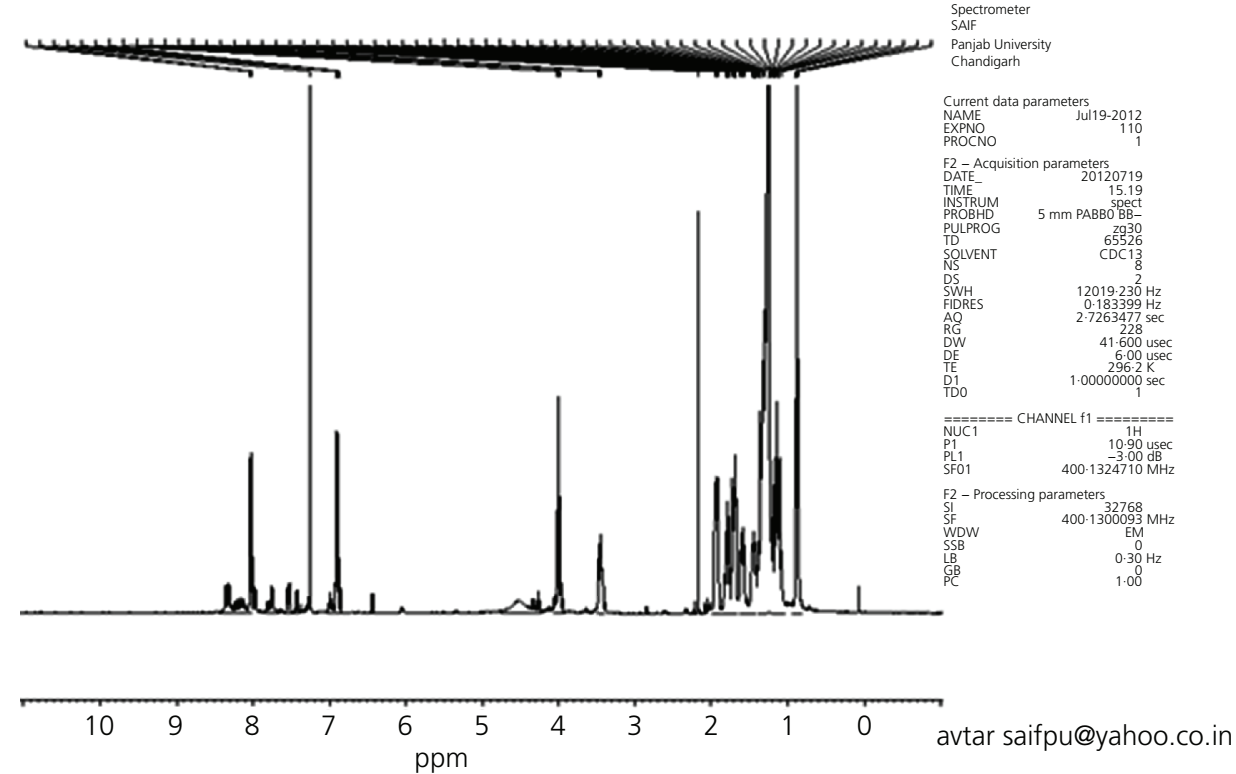

(d)

Figure 2. Continued

temperature of the mixture was in the range of $0-5^{\circ} \mathrm{C}$. The cold, dark yellow solution was added dropwise to a cold mixture of resorcinol $(1.1 \mathrm{~g}, 0.01 \mathrm{~mol})$, sodium hydroxide $(\mathrm{NaOH})(5 \mathrm{~g}$, $10 \%)$ and water $(50 \mathrm{ml})$, during which the temperature of the mixture was maintained below $8^{\circ} \mathrm{C}$. After the diazotising the solution, the material was stirred for about $30 \mathrm{~min}$ and then acidification with aqueous hydrochloric acid provided the crude product, which was collected by filtration, dried in air and crystallised several times from alcohol to yield $65 \%$ concentration. A similar procedure was utilised to synthesise 4-nitro-2 $2^{\prime}, 4^{\prime}$-dihydroxy azobenzene ( $68 \%$ concentration).

\subsubsection{Synthesis of 4-((4-chlorophenyl)diazenyl)-3-} hydroxyphenyl 6-alkoxy-2-naphthoate (series A) and 4-((4-nitrophenyl)diazenyl)-3-hydroxyphenyl 6-alkoxy-2-naphthoate (series B)

6-n-Alkoxy-2-naphthoic acids were heated under reflux with thionyl chloride to produce the corresponding acid chloride. 
Monoesters of series I and II were prepared by condensing equimolar quantities of the respective 4- $n$-alkoxybenzoyl chlorides with 4-chloro-2,4-dihydroxy azobenzene in dry pyridine through the Schotten-Baumann reaction following the method reported earlier. ${ }^{33}$

The monoesters of series I and II were prepared by condensing equimolar quantities of the respective 4- $n$-alkoxybenzoyl chlorides with 4-nitro-2,4-dihydroxy azobenzene in dry pyridine through the Schotten-Baumann reaction following the method reported earlier.

\subsubsection{Synthesis of bis(2-((4-chlorophenyl)diazenyl)-5-(6- alkoxy-2-naphthoyloxy)phenoxy) copper (II) (series MC) and bis(2-((4-nitrophenyl)diazenyl)-5-(6-alkoxy- 2-naphthoyloxy)phenoxy) copper (II) (series MD)}

Copper (II) chloride dihydrate $(0 \cdot 170 \mathrm{~g}, 1 \mathrm{mmol})$ was dissolved in methanol $(10 \mathrm{ml})$, and ammonia was added to it until the colour of

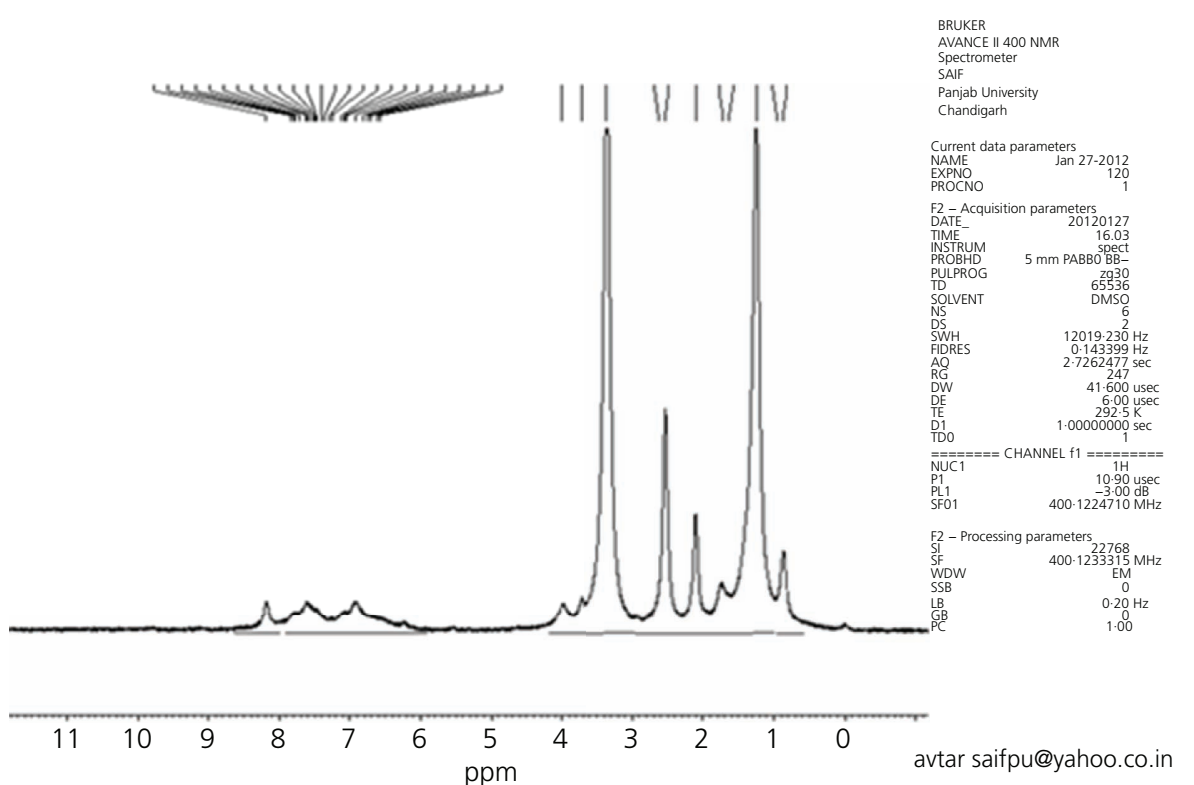

(a)

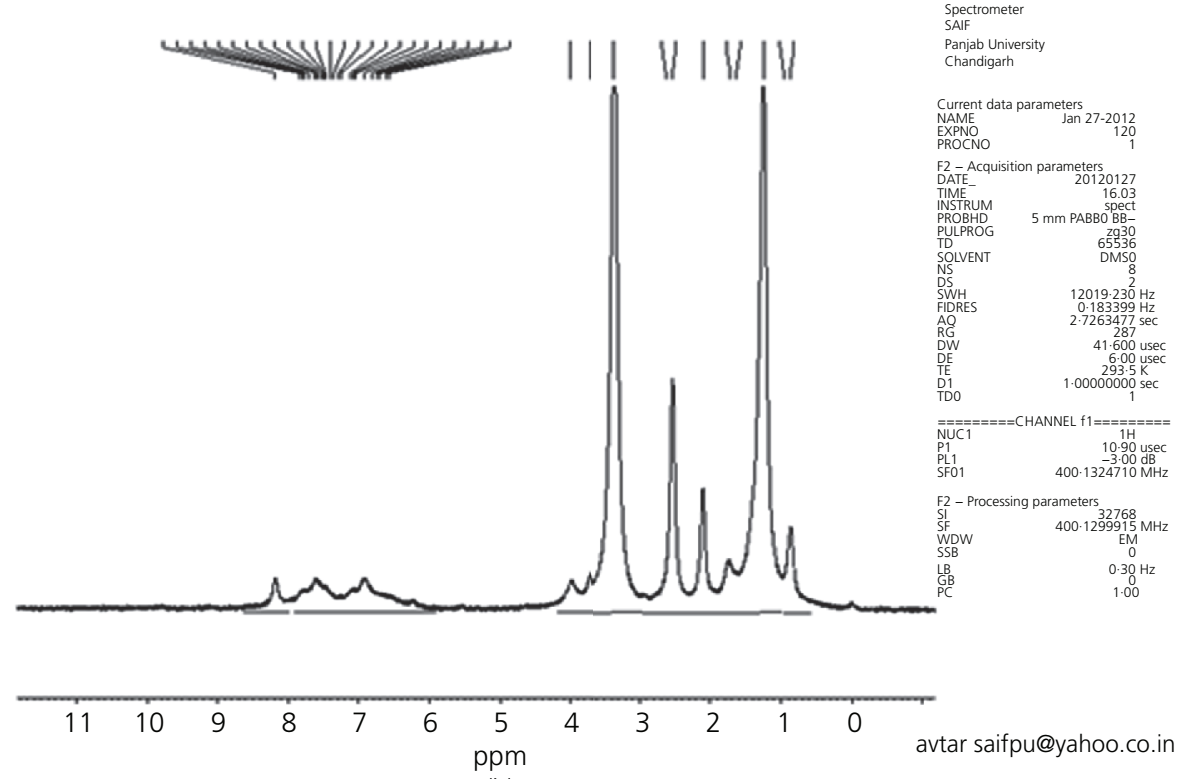

(b)

Figure 3. Proton NMR spectra of compounds (a) $M C_{18}$ and (b) $M D_{18}$ 
the solution became blue. Two millimoles of the appropriate ligand (series A or series B) was dissolved in methanol $(20 \mathrm{ml})$. The ligand solution was added to a metal solution, and the reaction mixture was refluxed for 3-4h. A brown-black precipitate was formed. The precipitate was filtered off and washed with methanol twice or thrice.

\subsection{Data: compound $A_{8}$ (4-((4-chlorophenyl)diazenyl)-3-} hydroxyphenyl 6-octyloxy-2-naphthoate (series A)) Molecular formula: $\mathrm{C}_{31} \mathrm{H}_{31} \mathrm{ClO}_{4} \mathrm{~N}_{2}$; yield: $80 \%$; clearing point: $209^{\circ} \mathrm{C}$; ultraviolet (UV) (chloroform $\left(\mathrm{CHCl}_{3}\right)$ ) $\lambda_{\max }$ : $258 \mathrm{~nm}$; elemental analysis data: found: carbon (C): 70.38\%, hydrogen
$(\mathrm{H}): 5 \cdot 68 \%$, nitrogen $(\mathrm{N}): 5 \cdot 00 \%$; calculated: carbon: $70 \cdot 11 \%$, hydrogen: $5 \cdot 88 \%$, nitrogen: $5 \cdot 28 \%$; Fourier transform infrared (FT-IR) (potassium bromide (KBr)): $v_{\max }: \mathrm{cm}^{-1}: 3351(\mathrm{O}-\mathrm{H}$ stretching of $-\mathrm{OH}$ group attached to aromatic ring), $3042(\mathrm{C}-\mathrm{H}$ stretching aromatic), 2931, 2855 (C-H stretching aliphatic), 1732 $(\mathrm{C}=\mathrm{O}$ stretching of ester linkage), $1606(\mathrm{~N}=\mathrm{N}$ Schiff base $), 1542$ $(\mathrm{C}=\mathrm{C}$ stretching of aromatic), $1219 \quad(\mathrm{C}-\mathrm{O}-\mathrm{C}$ asymmetric stretching), 1057 (C-O-C symmetric stretching); proton $\left({ }^{l} H\right)$ nuclear magnetic resonance (NMR) $(400 \mathrm{MHz}$, deuterated chloroform $\left.\left(\mathrm{CDCl}_{3}\right)\right)$ : $0 \cdot 86-0 \cdot 89$ parts per million (ppm) $\left(\mathrm{t}, \mathrm{CH}_{3}\right.$ of aliphatic chain), $1.26-1.84 \mathrm{ppm}\left(\mathrm{m}, \mathrm{CH}_{2}\right.$ of aliphatic chain),

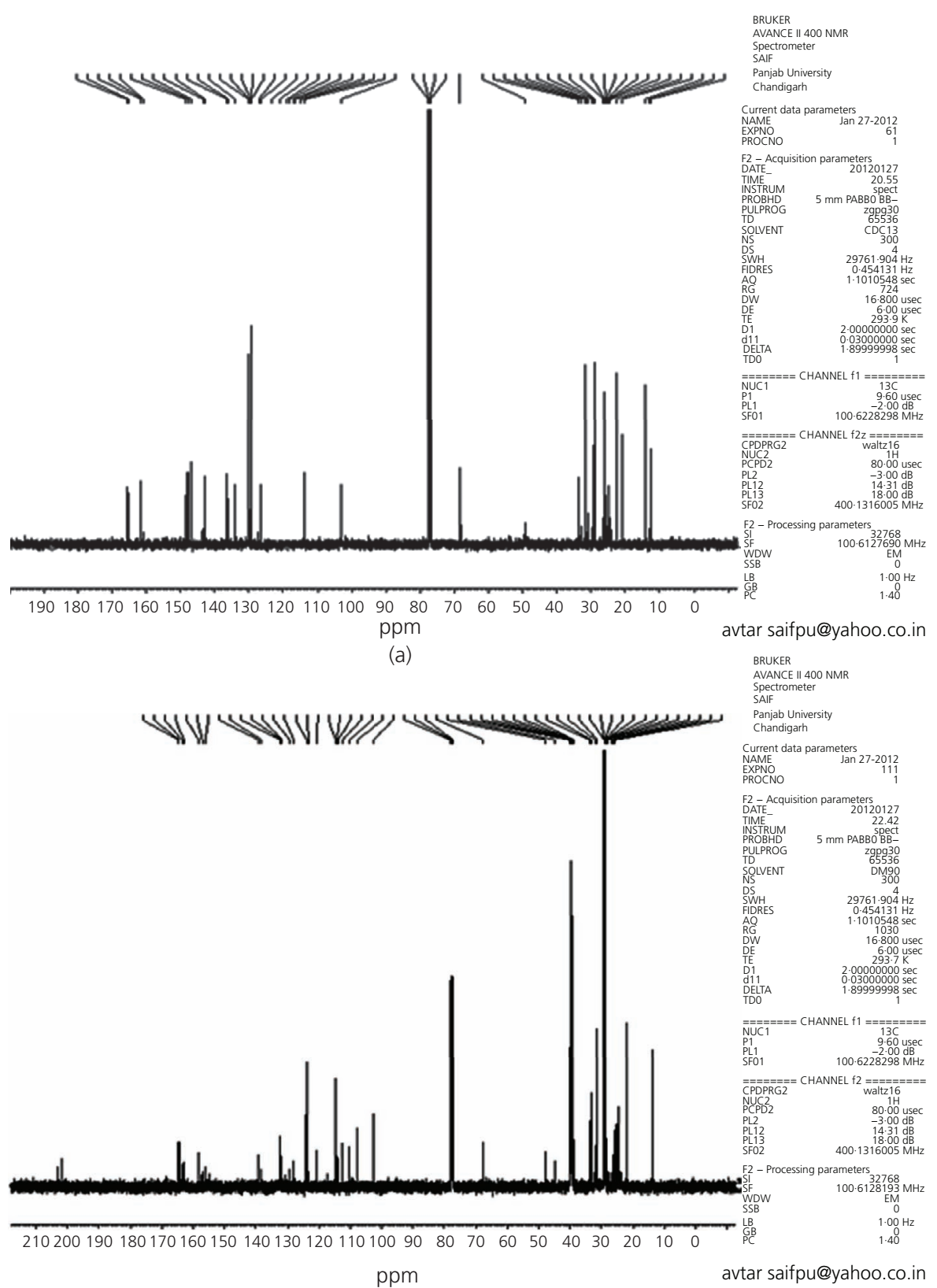

(b)

Figure 4. Carbon-13 NMR spectra of compounds (a) $A_{8}$, (b) $A_{16}$, (c) $B_{8}$ and (d) $B_{16}$ (continued on next page) 

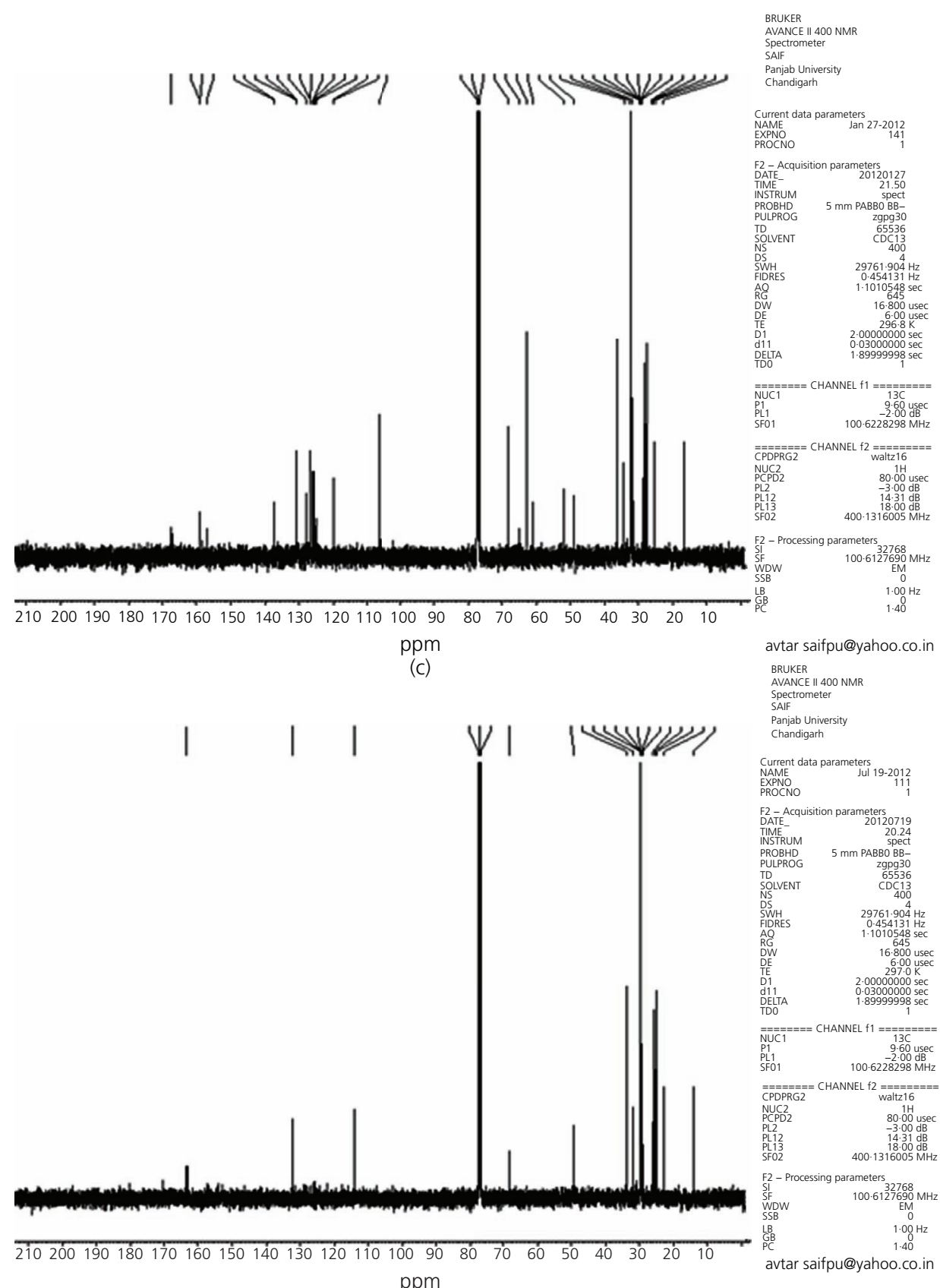

(d)

Figure 4. Continued

4.05-4.08 ppm (t, $\mathrm{OCH}_{2}$ attached with naphthalene ring), $7 \cdot 10-8 \cdot 72 \mathrm{ppm}$ (m, phenyl multiplet), $11 \cdot 25 \mathrm{ppm}$ (s, OH proton of phenyl); carbon-13 $\quad\left({ }^{13} \mathrm{C}\right) \quad N M R$ (deuterated chloroform): $14.13 \mathrm{ppm}\left(\mathrm{CH}_{3}\right.$ of aliphatic chain), $22.63-33.85 \mathrm{ppm}\left(\mathrm{CH}_{2}\right.$ of aliphatic chain), $68 \cdot 23 \mathrm{ppm}\left(\mathrm{OCH}_{2}\right.$ carbon of alkoxy attached with naphthalene ring), $165 \cdot 34 \mathrm{ppm}(\mathrm{C}=\mathrm{O}-$ of ester linkage); mass (gas chromatography-mass spectrometry (GC-MS)): MS positive electrospray (ES+) $\mathrm{m} / \mathrm{z}$ (relative intensity \%): 531.04 (M+2) ${ }^{+} \mathrm{m} / \mathrm{z}$.
2.4 Data: compound $\mathrm{B}_{16}$ (3-hydroxy-4-((4-nitrophenyl) diazenyl)phenyl 6-hexadecyloxy-2-naphthoate (series B))

Molecular formula: $\mathrm{C}_{39} \mathrm{H}_{47} \mathrm{O}_{3} \mathrm{~N}_{3}$; yield: $78 \%$; clearing point: $212{ }^{\circ} \mathrm{C}$; $U V$ (chloroform) $\lambda_{\max }$ : $254 \mathrm{~nm}$; elemental analysis data: found: carbon: $71.91 \%$, hydrogen: $7 \cdot 08 \%$, nitrogen: $6 \cdot 15 \%$; calculated: carbon: $71 \cdot 64 \%$, hydrogen: $7 \cdot 25 \%$, nitrogen: $6 \cdot 43 \%$; FT-IR (potassium bromide): $v_{\max }: \mathrm{cm}^{-1}: 3327(\mathrm{O}-\mathrm{H}$ stretching of $-\mathrm{OH}$ 

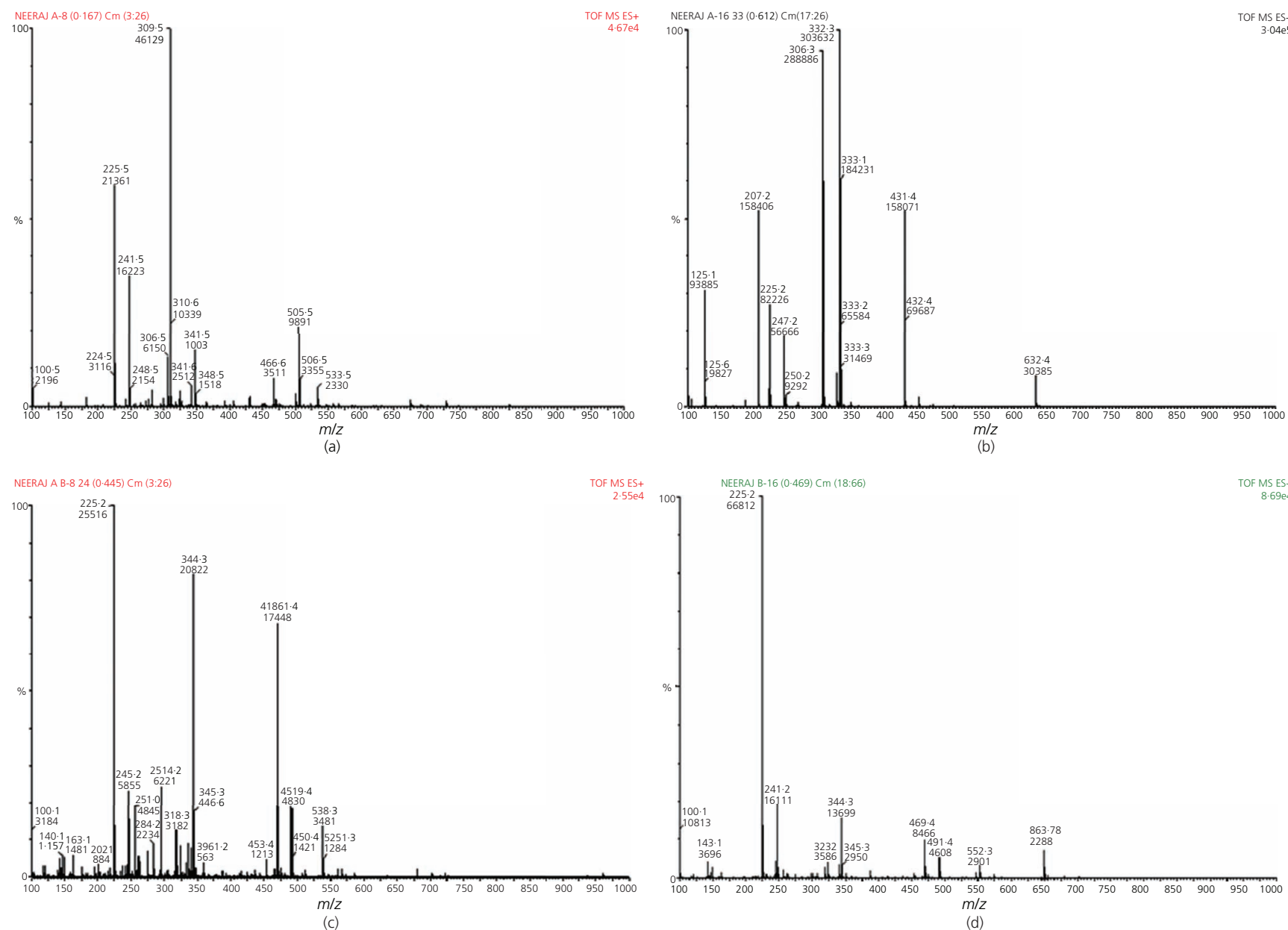

Figure 5. Mass spectra of compounds (a) $A_{8}$, (b) $A_{16}$, (c) $B_{8}$ and (d) $B_{16}$

group attached to aromatic ring), 3034 (C-H stretching aromatic), 2921, 2850 (C-H stretching aliphatic), 1678 ( $\mathrm{C}=\mathrm{O}$ stretching of ester linkage), $1608(\mathrm{~N}=\mathrm{N}$ Schiff base), $1626(\mathrm{C}=\mathrm{C}$ stretching of aromatic), 1255 (C-O-C asymmetric stretching), 1045 (C-O-C symmetric stretching); proton $N M R$ (400 MHz, deuterated chloroform): 0.85-0.89 ppm (t, $\mathrm{CH}_{3}$ of aliphatic chain), $1.29-1 \cdot 81 \mathrm{ppm}\left(\mathrm{m}, \mathrm{CH}_{2}\right.$ of aliphatic chain), $4.01-4.03 \mathrm{ppm} \mathrm{(t,} \mathrm{OCH}_{2}$ attached with naphthalene ring), 7.20-8.79 ppm ( $\mathrm{m}$, phenyl multiplet), $11.39 \mathrm{ppm}$ (s, OH proton of phenyl); carbon-13 NMR (deuterated chloroform): $14 \cdot 13 \mathrm{ppm}\left(\mathrm{CH}_{3}\right.$ of aliphatic chain), $22 \cdot 70-33 \cdot 85 \mathrm{ppm}\left(\mathrm{CH}_{2}\right.$ of aliphatic chain), $68 \cdot 24 \mathrm{ppm}\left(\mathrm{OCH}_{2}\right.$ carbon of alkoxy attached with naphthalene ring), $163 \cdot 29 \mathrm{ppm}(C=\mathrm{O}-$ of ester linkage); mass ( $G C$ $M S):$ MS ES $+m / z$ (relative intensity \%): $653 \cdot 8(\mathrm{M}+3)^{+} \mathrm{m} / \mathrm{z}$.

\subsection{Data: compound $\mathrm{MC}_{18}$ (bis(2-((4-chlorophenyl) diazenyl)-5-(6-octadecyloxy-2-naphthoyloxy) phenoxy) copper (II) (series MC))}

Molecular formula: $\mathrm{C}_{82} \mathrm{H}_{100} \mathrm{Cl}_{2} \mathrm{O}_{8} \mathrm{~N}_{4} \mathrm{Cu}$; yield: $70 \%$; heating up to: $205^{\circ} \mathrm{C}$; $U V$ (chloroform) $\lambda_{\max }: 254,300 \mathrm{~nm}$; elemental analysis data: found: carbon: $70 \cdot 38 \%$, hydrogen: $7 \cdot 42 \%$, nitrogen: $3 \cdot 76 \%$, copper: $4 \cdot 30 \%$; calculated: carbon: $70 \cdot 14 \%$, hydrogen: $7 \cdot 18 \%$, nitrogen:
3.99\%, copper: $4.53 \%$; FT-IR (potassium bromide): $v_{\max }: \mathrm{cm}^{-1}$ : 3078 (C-H stretching aromatic), 2925, 2865 (C-H stretching aliphatic), 1738 ( $\mathrm{C}=\mathrm{O}$ stretching of ester linkage), $1624(\mathrm{~N}=\mathrm{N}$ Schiff base), $1582(\mathrm{C}=\mathrm{C}$ stretching of aromatic), $1211(\mathrm{C}-\mathrm{O}-\mathrm{C}$ asymmetric stretching), 1042 (C-O-C symmetric stretching); proton NMR (400 MHz, deuterated chloroform): $0 \cdot 85-0.89 \mathrm{ppm}$ ( $\mathrm{t}, \mathrm{CH}_{3}$ of aliphatic chain), $1 \cdot 25-1 \cdot 89 \mathrm{ppm}$ (m, $\mathrm{CH}_{2}$ of aliphatic chain), $4 \cdot 09-4 \cdot 11 \mathrm{ppm}$ (t, $\mathrm{OCH}_{2}$ attached with naphthalene ring), $7 \cdot 10-8 \cdot 70 \mathrm{ppm}$ (m, phenyl multiplet); carbon-13 NMR (deuterated chloroform): $14 \cdot 25 \mathrm{ppm}\left(\mathrm{CH}_{3}\right.$ of aliphatic chain), 22.79-33.89 ppm $\left(\mathrm{CH}_{2}\right.$ of aliphatic chain), $68.46 \mathrm{ppm}\left(\mathrm{OCH}_{2}\right.$ carbon of alkoxy attached with naphthalene ring), $166.43 \mathrm{ppm}(C=\mathrm{O}-$ of ester linkage); mass (GC-MS): MS ES+ $m / z$ (relative intensity \%): $1404 \cdot 14(\mathrm{M}+3)^{+} \mathrm{m} / \mathrm{z}$.

\subsection{Data: compound $\mathrm{MD}_{18}$ (bis-\{4-[(5-hydroxy-3- methyl-1-p-tolyl-4,5-dihydro-1H-pyrazolyl) methyleneamino]phenyl3-(4-n-heptyloxyphenyl) acrylate\}copper (II) (series MD)}

Molecular formula: $\mathrm{C}_{82} \mathrm{H}_{100} \mathrm{O}_{12} \mathrm{~N}_{6} \mathrm{Cu}$; yield: $66 \%$; heating up to: $203^{\circ} \mathrm{C}$; UV (chloroform) $\lambda_{\max }: 252,304 \mathrm{~nm}$; elemental analysis 

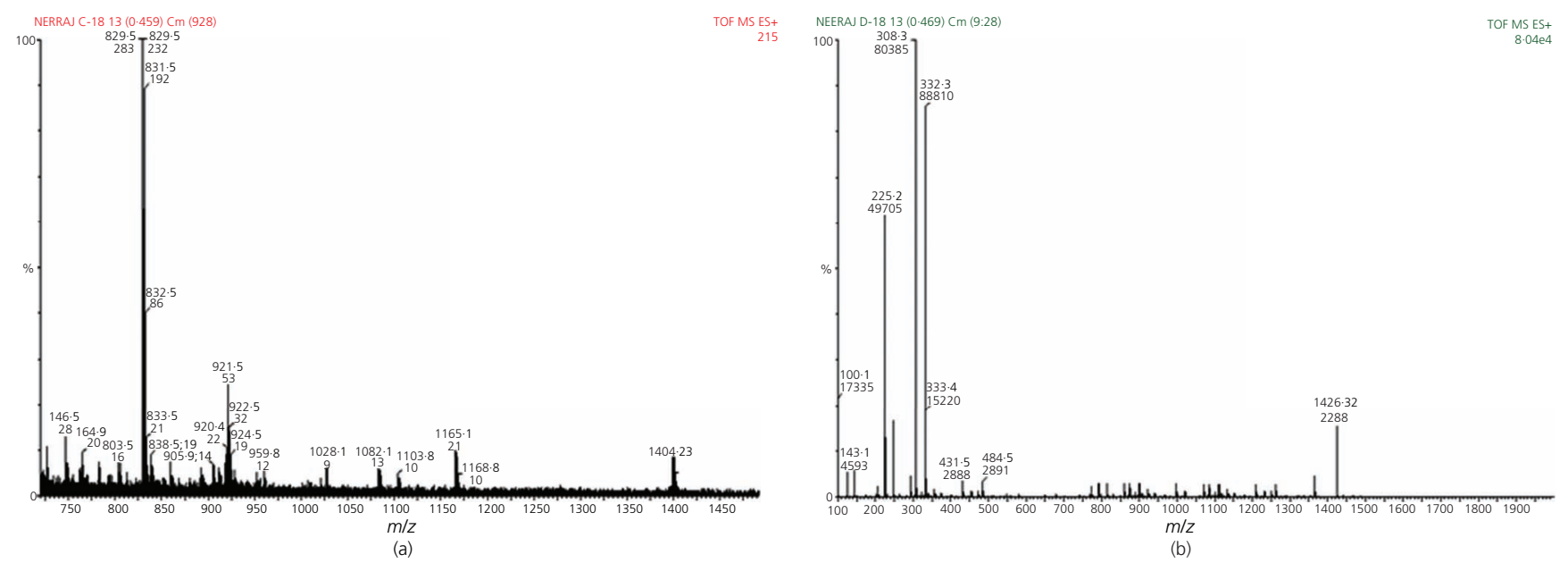

Figure 6. Mass spectra of compounds (a) $M C_{18}$ and (b) $M D_{18}$

(I) Synthesis of 6-alkoxy-2-naphthoic acid

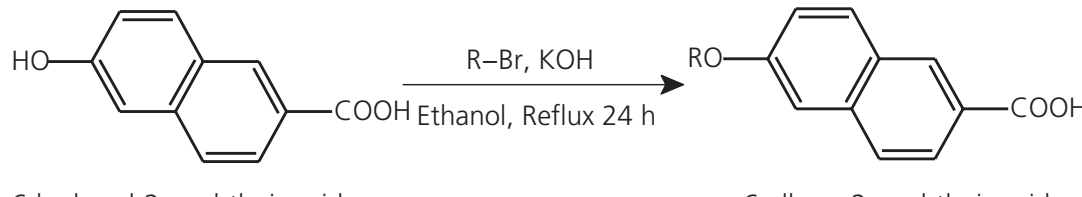

6-hydroxyl-2-naphthoic acid

6-alkoxy-2-naphthoic acid

Where $\mathrm{R}=\mathrm{C}_{n} \mathrm{H}_{2 n+1}, n=1-8,10,12,14,16,18[\mathrm{~A}]$

(II) Synthesis of 4-chloro/nitro-2', 4'-dihydroxy azobenzene (B)

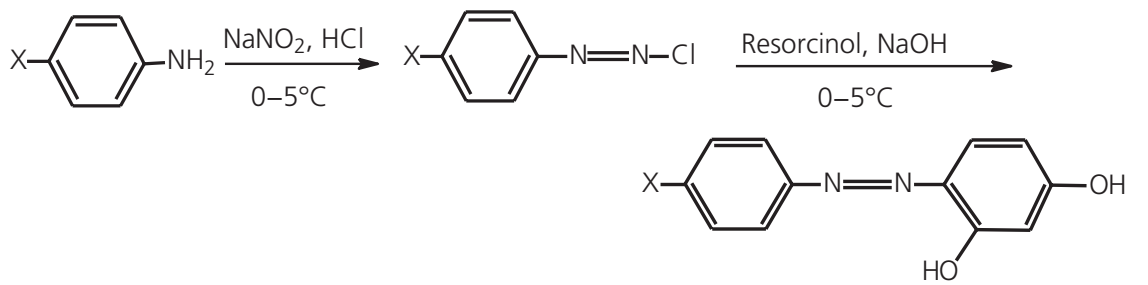

4-chloro/nitro-2', 4'-dihydroxy azobenzene [B]

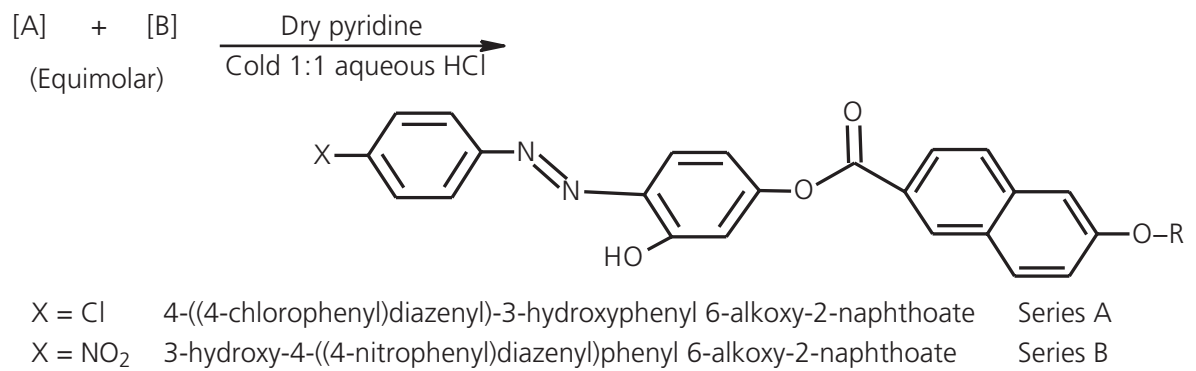

Scheme 1. Synthetic route for the compounds of series $A$ and series $B$ 

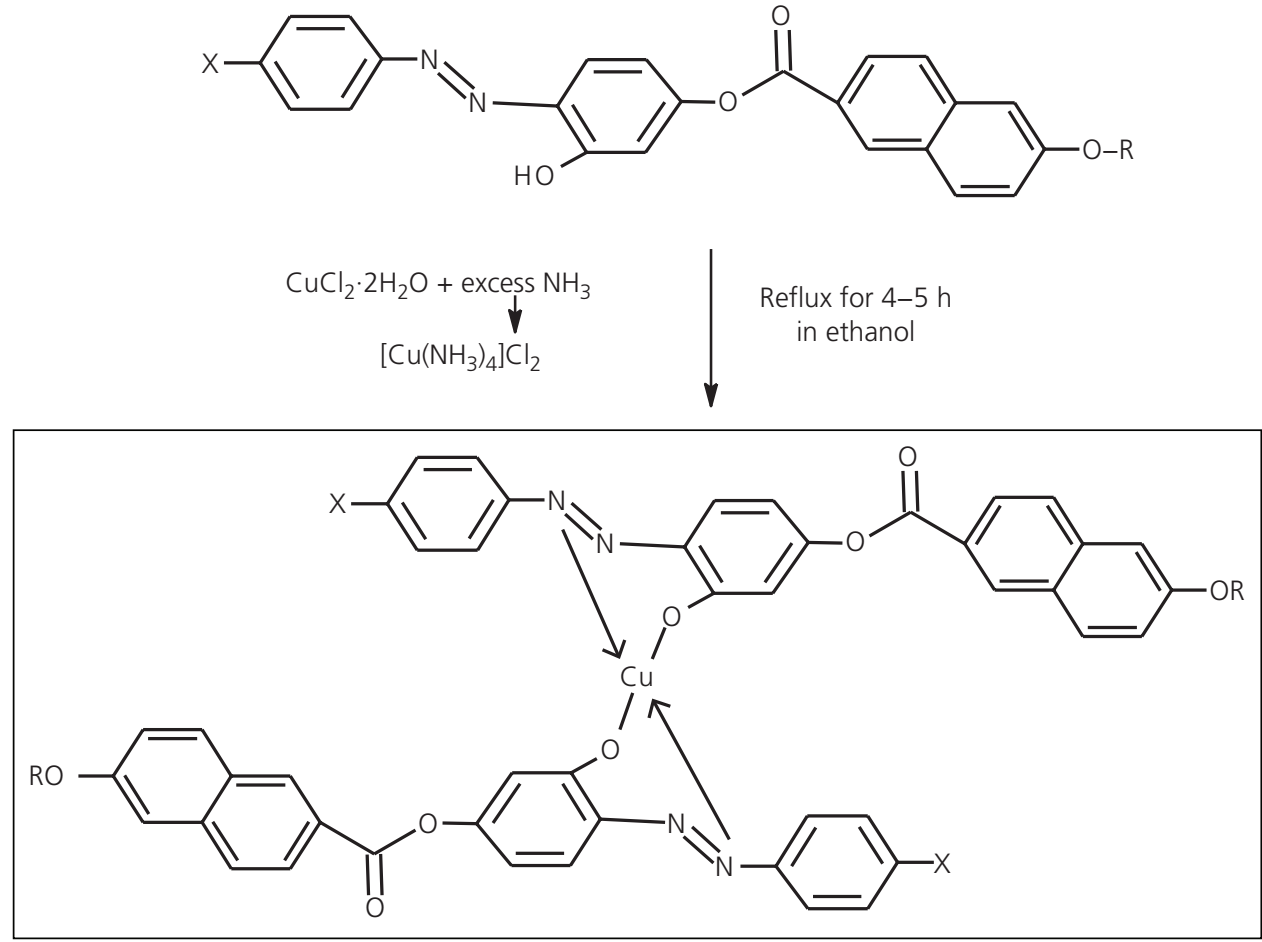

Where $\mathrm{X}=\mathrm{Cl}$; bis(2-((4-chlorophenyl)diazenyl)-5-(6-alkoxy-2-naphthoyloxy)phenoxy) Cu (II) (series MC) $\mathrm{X}=\mathrm{NO}_{2}$; bis(2-((4-nitrophenyl)diazenyl)-5-(6-alkoxy-2-naphthoyloxy)phenoxy) $\mathrm{Cu}$ (II) (series MD)

Scheme 2. Synthetic route for the compounds MC and MD

Table 1. Transition temperature data of series $\mathrm{A}:{ }^{\circ} \mathrm{C}$

\begin{tabular}{|c|c|c|c|c|c|c|c|c|}
\hline \multirow{2}{*}{ Code } & \multirow{2}{*}{$\begin{array}{c}\mathrm{R}=\mathrm{C}_{n} \mathrm{H}_{2 n+1} \\
n=\end{array}$} & \multicolumn{7}{|c|}{ Transition temperature: ${ }^{\circ} \mathrm{C}$} \\
\hline & & $\mathrm{Cr}$ & & $\mathrm{Sm}$ & & $\mathrm{N}$ & & I \\
\hline$A_{2}$ & 2 & • & - & • & 191 & • & 225 & • \\
\hline$A_{3}$ & 3 & $\bullet$ & - & - & 188 & $\bullet$ & 222 & - \\
\hline$A_{4}$ & 4 & $\bullet$ & - & $\bullet$ & $(185)^{a}$ & - & 220 & - \\
\hline$A_{5}$ & 5 & $\bullet$ & - & • & 183 & - & 218 & - \\
\hline$A_{6}$ & 6 & - & - & - & 180 & - & 213 & - \\
\hline$A_{7}$ & 7 & $\bullet$ & - & - & 179 & - & 211 & $\bullet$ \\
\hline$A_{8}$ & 8 & $\bullet$ & 93 & $\bullet$ & 177 & $\bullet$ & 209 & • \\
\hline$A_{10}$ & 10 & $\bullet$ & $(91)^{\mathrm{a}}$ & - & 164 & $\bullet$ & 195 & $\bullet$ \\
\hline$A_{12}$ & 12 & • & 88 & • & 152 & • & 189 & • \\
\hline$A_{14}$ & 14 & • & 87 & • & 142 & • & 184 & • \\
\hline$A_{16}$ & 16 & • & 86 & • & 133 & • & 176 & • \\
\hline$A_{18}$ & 18 & • & 80 & • & 118 & • & 173 & • \\
\hline
\end{tabular}

${ }^{a}$ Monotropic phase

Cr, crystalline; Sm, smectic; N, nematic; I, isotropic

- indicates the state or particular phase

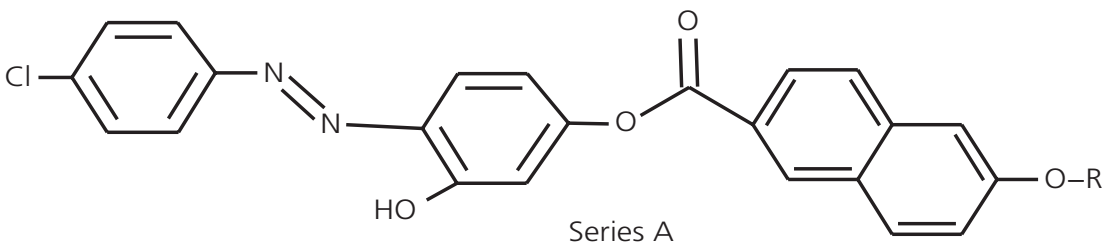


Table 2. Transition temperature data of series $\mathrm{B}:{ }^{\circ} \mathrm{C}$

\begin{tabular}{|c|c|c|c|c|c|c|c|c|}
\hline \multirow{2}{*}{ Code } & \multirow{2}{*}{$\begin{array}{c}\mathrm{R}=\mathrm{C}_{n} \mathrm{H}_{2 n+1} \\
n=\end{array}$} & \multicolumn{7}{|c|}{ Transition temperature: ${ }^{\circ} \mathrm{C}$} \\
\hline & & $\mathrm{Cr}$ & & $\mathrm{Sm}$ & & N & & I \\
\hline $\mathrm{B}_{2}$ & 2 & - & - & - & 164 & - & 235 & $\bullet$ \\
\hline $\mathrm{B}_{3}$ & 3 & - & - & - & 157 & - & 232 & - \\
\hline $\mathrm{B}_{4}$ & 4 & - & - & - & 152 & - & 229 & - \\
\hline $\mathrm{B}_{5}$ & 5 & - & - & - & $(148)^{a}$ & - & 224 & • \\
\hline $\mathrm{B}_{6}$ & 6 & - & - & - & 143 & - & 220 & $\bullet$ \\
\hline $\mathrm{B}_{7}$ & 7 & $\bullet$ & 109 & $\bullet$ & 140 & - & 217 & $\bullet$ \\
\hline $\mathrm{B}_{8}$ & 8 & $\bullet$ & 106 & $\bullet$ & 133 & - & 213 & $\bullet$ \\
\hline$B_{10}$ & 10 & • & 104 & • & 130 & • & 207 & • \\
\hline$B_{12}$ & 12 & • & $(103)^{a}$ & • & $(127)^{a}$ & • & 203 & • \\
\hline $\mathrm{B}_{14}$ & 14 & • & 101 & • & 123 & • & 199 & • \\
\hline$B_{16}$ & 16 & • & 100 & • & 121 & • & 195 & • \\
\hline$B_{18}$ & 18 & $\bullet$ & 95 & • & 115 & • & 186 & • \\
\hline
\end{tabular}

${ }^{\text {a }}$ Monotropic phase

- indicates the state or particular phase

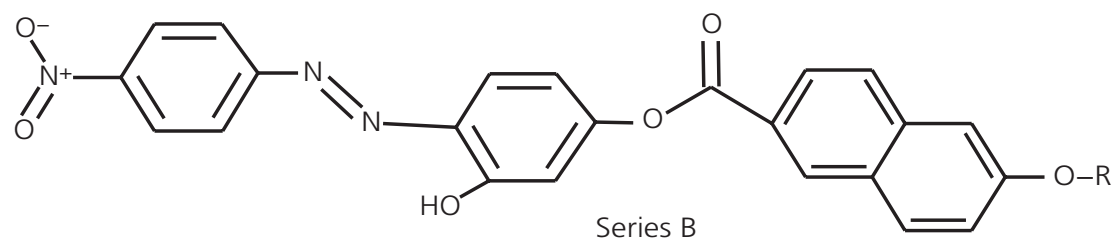

data: found: carbon: $69 \cdot 35 \%$, hydrogen: $7 \cdot 21 \%$, nitrogen: $5 \cdot 54 \%$, copper: $4 \cdot 30 \%$; calculated: carbon: $69 \cdot 10 \%$, hydrogen: $7 \cdot 07 \%$, nitrogen: $5 \cdot 90 \%$, copper: $4 \cdot 46 \%$; FT-IR (potassium bromide): $v_{\max }: \mathrm{cm}^{-1}: 3080(\mathrm{C}-\mathrm{H}$ stretching aromatic), 2918, $2825(\mathrm{C}-\mathrm{H}$ stretching aliphatic), $1753(\mathrm{C}=\mathrm{O}$ stretching of ester linkage $), 1626$ $(\mathrm{N}=\mathrm{N}$ Schiff base), $1584(\mathrm{C}=\mathrm{C}$ stretching of aromatic), 1202 (C-O-C asymmetric stretching), 1038 (C-O-C symmetric stretching); proton $N M R$ (400 MHz, deuterated chloroform): $0.85-0.88 \mathrm{ppm}$ (t, $\mathrm{CH}_{3}$ of aliphatic chain), $1.25-1.87 \mathrm{ppm}$ (m, $\mathrm{CH}_{2}$ of aliphatic chain), $4 \cdot 10-4 \cdot 12 \mathrm{ppm}\left(\mathrm{t}, \mathrm{OCH}_{2}\right.$ attached with naphthalene ring), $7 \cdot 12-8 \cdot 72 \mathrm{ppm}$ (m, phenyl multiplet); carbon-13 NMR (deuterated chloroform): $14 \cdot 19 \mathrm{ppm}\left(\mathrm{CH}_{3}\right.$ of aliphatic chain), 22.94-33.97 ppm $\left(\mathrm{CH}_{2}\right.$ of aliphatic chain), $68.45 \mathrm{ppm}\left(\mathrm{OCH}_{2}\right.$ carbon of alkoxy attached with naphthalene ring), $168.02 \mathrm{ppm}(C=\mathrm{O}-$ of ester linkage); mass $(G C-M S)$ : $\mathrm{MS}$ ES $+m / z$ (relative intensity \%): $1425 \cdot 25(\mathrm{M}+3)^{+} \mathrm{m} / \mathrm{z}$.

The FT-IR, proton NMR, carbon-13 NMR and mass spectra of compounds $\mathrm{A}_{8}, \mathrm{~A}_{16}, \mathrm{~B}_{8}, \mathrm{~B}_{16}, \mathrm{MC}_{18}$ and $\mathrm{MD}_{18}$ are shown in Figures 1-6.

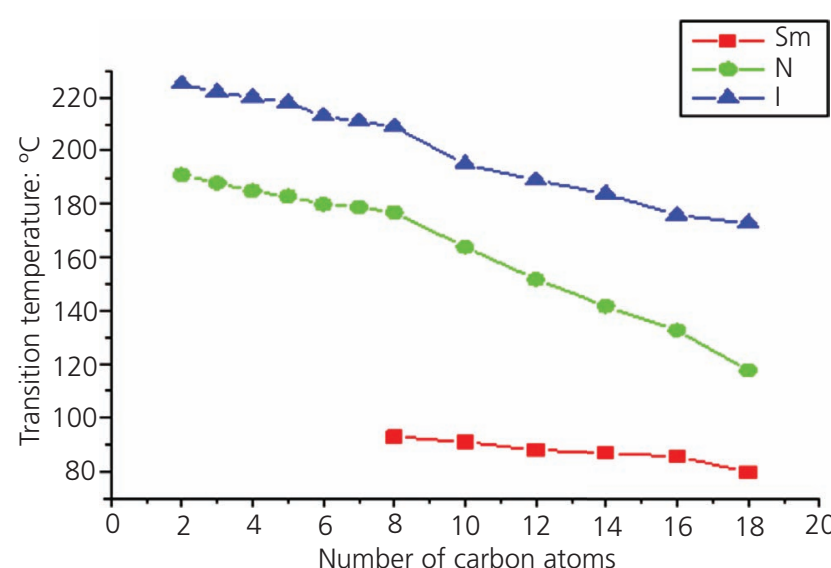

(a)

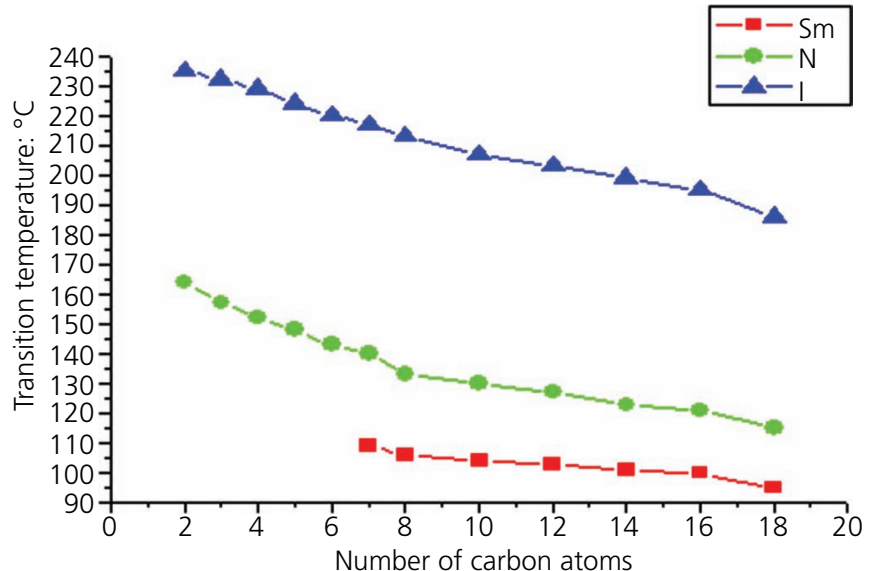

(b)

Figure 7. (a) Transition temperature plotted against number of carbon atoms in alkoxy chain of series $A$; (b) transition temperature plotted against number of carbon atoms in alkoxy chain of series $B$ 


\subsection{Technique}

Elemental analysis (carbon, hydrogen, nitrogen) was performed using a Thermo Scientific Flash 2000 analyser (Thermo Fisher Scientific Inc., Waltham, MA, USA) at Gujarat Narmada Valley Fertilizer Company Ltd (Bharuch, India). Infrared spectra were recorded with a Thermo Scientific Nicolet iS10 FT-IR spectrophotometer (Thermo Fisher Scientific Inc.) at the Department of Chemistry, Veer Narmad South Gujarat University, in the frequency range of $4000-400 \mathrm{~cm}^{-1}$ with the samples embedded in potassium bromide discs. The proton NMR and carbon-13 NMR spectra of the compounds were recorded with a Bruker Avance II 400 NMR spectrometer using deuterated chloroform as a solvent and tetramethylsilane as an internal reference at the Sophisticated Analytical Instrument Facilities (Saif), Chandigarh. The electron ionisation mass spectra of the compound were recorded with a Finnigan Mat-8230 mass spectrometer (Bremen, Germany) also at Saif, Chandigarh. A Merck 60 F524 thin-layer plate (Merck (India) Pvt. Ltd., Mumbai, India) was used for thin-layer chromatography (TLC) and examined under short-wave UV light. The UV-visible spectra of a $10^{-5} \mathrm{M}$ solution of the samples using chloroform as the solvent were recorded with a Thermo Scientific Evolution 300 UV-visible spectrometer (Thermo Fisher Scientific Inc.) in the range of $200-800 \mathrm{~nm}$. Thermal analyses and differential scanning calorimetry (DSC) of the LC compounds were carried out at Mettler Toledo India Pvt. Ltd., Powai, Mumbai. DSC analysis was performed using a Mettler Toledo DSC-1 instrument (Geneva, Switzerland) at a heating rate of $10^{\circ} \mathrm{C} / \mathrm{min}$ in a nitrogen $\left(\mathrm{N}_{2}\right)$ atmosphere. Some of the DSC samples were analysed at the Sophisticated Instrumentation Centre for Applied Research and Testing, Vallabh Vidhyanagar, on a PerkinElmer DSC analyser (PerkinElmer (India) Pvt. Ltd., Thane (West), India). Optical microscopy studies were carried out with a Nikon Eclipse 50i Pol microscope (Japan) equipped with a Linkam Analysa-LTS 420 hot stage (London, UK) at the Department of Chemistry, Veer Narmad South Gujarat University. The textures of the compounds were observed using polarised light with crossed polariser with the sample in a thin film sandwiched between a glass slide and a coverslip.

\section{Results and discussion}

In the present study, 12 homologues from each of the two (ligand) series 4-((4-chlorophenyl)diazenyl)-3-hydroxyphenyl 6-alkoxy-2naphthoate (series A) and 3-hydroxy-4-((4-nitrophenyl)diazenyl) phenyl 6-hexadecyloxy-2-naphthoate (series B) were synthesised as per the synthetic route given in Scheme 1. The authors also synthesised seven metallomesogens from each of the two complex series bis(2-((4-chlorophenyl)diazenyl)-5-(6-alkoxy-2-naphthoyloxy) phenoxy) copper (II) (series MC) and bis(2-((4-nitrophenyl)diazenyl)5-(6-alkoxy-2-naphthoyloxy)phenoxy) copper (II) (series MD) as per the synthetic route given in Scheme 2.

These compounds were subjected to elemental analysis. The elemental analysis data agreed with the composition of the expected structure. The metal, copper, was estimated gravimetrically as copper (II) oxide $(\mathrm{CuO})$. Each compound was subjected to TLC (Merck Kicsel gel 60 F254 pre-coated plates). It shows one spot, indicating a single compound. All the compounds were purified by column chromatography on silica gel (80-120 mesh) using a mixture of ethyl acetate/petroleum ether (7:3) followed by repeated recrystallisation from ethanol.

\subsection{Thermal and phase behaviour}

The melting points and transition temperatures of the LC compounds of series A and series B are given in Tables 1 and 2 . Optical microscopy revealed that series A compounds exhibit the enantiometric nematic phase $\left(\mathrm{C}_{2}, \mathrm{C}_{3}, \mathrm{C}_{5}-\mathrm{C}_{8}, \mathrm{C}_{10}, \mathrm{C}_{12}, \mathrm{C}_{14}, \mathrm{C}_{16}\right.$ and $\mathrm{C}_{18}$ ) homologues except for the $\mathrm{C}_{4}$ compound. The $\mathrm{C}_{4}$ homologue $\left(\mathrm{C}_{4} \mathrm{H}_{9}\right)$ exhibits a monotropic nature. The smectic $\mathrm{A}$ phase starts from compound $\mathrm{C}_{8}$ and persists up to the last member of the series. Compound $\mathrm{C}_{10}$ exhibits a monotropic smectic $\mathrm{A}$ phase. The plot of transition temperature against the number of carbon atoms in the alkoxy chain (Figure 7(a)) exhibits no odd-even effect for any transition temperature. The transition temperature of smectic A phase decreased as the series was ascended. This was due to the increase in the number of $-\mathrm{CH}_{2}-$ groups in the alkoxy straight chain - that is, the dilution effect. ${ }^{34}$ Similarly, the $\mathrm{Cr}-\mathrm{N}$ and $\mathrm{Sm}-\mathrm{A}-\mathrm{N}$ transition temperatures also show a decreasing tendency as the series ascends.

In the case of series $\mathrm{B}$, the $\mathrm{C}_{2}-\mathrm{C}_{18}$ (ethoxy to $n$-octadecyloxy) derivatives exhibit an enantiotropic nematic mesophase as in series $A$ except that the $C_{5}$ and $C_{12}$ derivatives display a monotropic nematic phase. The smectic A mesophase starts from the $\mathrm{C}_{7}$ derivative and persists up to the last member of the homologous series except that the $\mathrm{C}_{12}$ derivative exhibits a
Table 3. Transition temperature data of series $\mathrm{MC}:{ }^{\circ} \mathrm{C}$

\begin{tabular}{lcccccc} 
& $\mathbf{R}=\mathrm{C}_{\boldsymbol{n}} \mathrm{H}_{2 n+1}$ & \multicolumn{5}{c}{ Transition temperature: ${ }^{\circ} \mathrm{C}$} \\
\cline { 3 - 6 } & $\boldsymbol{n}=$ & $\mathrm{Cr}$ & & $\mathrm{N}$ & & I \\
$\mathrm{MC}_{7}$ & 7 & $\bullet$ & - & $\bullet$ & 230 & $\bullet$ \\
$\mathrm{MC}_{8}$ & 8 & $\bullet$ & - & $\bullet$ & 227 & $\bullet$ \\
$\mathrm{MC}_{10}$ & 10 & $\bullet$ & - & $\bullet$ & 220 & $\bullet$ \\
$\mathrm{MC}_{12}$ & 12 & $\bullet$ & 129 & $\bullet$ & 217 & $\bullet$ \\
$\mathrm{MC}_{14}$ & 14 & $\bullet$ & - & $\bullet$ & 214 & $\bullet$ \\
$\mathrm{MC}_{16}$ & 16 & $\bullet$ & 138 & $\bullet$ & 209 & $\bullet$ \\
$\mathrm{MC}_{18}$ & 18 & $\bullet$ & 142 & $\bullet$ & 205 & $\bullet$
\end{tabular}

- indicates the state or particular phase
Table 4. Transition temperature data of series MD: ${ }^{\circ} \mathrm{C}$

\begin{tabular}{|c|c|c|c|c|c|c|}
\hline \multirow{2}{*}{ Code } & \multirow{2}{*}{$\begin{array}{c}\mathrm{R}=\mathrm{C}_{n} \mathrm{H}_{2 n+1} \\
n=\end{array}$} & \multicolumn{5}{|c|}{ Transition temperature: ${ }^{\circ} \mathrm{C}$} \\
\hline & & $\mathrm{Cr}$ & & $\mathbf{N}$ & & I \\
\hline $\mathrm{MD}_{7}$ & 7 & $\bullet$ & - & $\bullet$ & 238 & $\bullet$ \\
\hline $\mathrm{MD}_{8}$ & 8 & $\bullet$ & - & $\bullet$ & 234 & $\bullet$ \\
\hline $\mathrm{MD}_{10}$ & 10 & $\bullet$ & 118 & $\bullet$ & 225 & $\bullet$ \\
\hline $\mathrm{MD}_{12}$ & 12 & $\bullet$ & - & $\bullet$ & 216 & $\bullet$ \\
\hline $\mathrm{MD}_{14}$ & 14 & $\bullet$ & - & - & 207 & $\bullet$ \\
\hline $\mathrm{MD}_{16}$ & 16 & $\bullet$ & 127 & $\bullet$ & 199 & $\bullet$ \\
\hline $\mathrm{MD}_{18}$ & 18 & $\bullet$ & 132 & $\bullet$ & 185 & $\bullet$ \\
\hline
\end{tabular}

- indicates the state or particular phase 


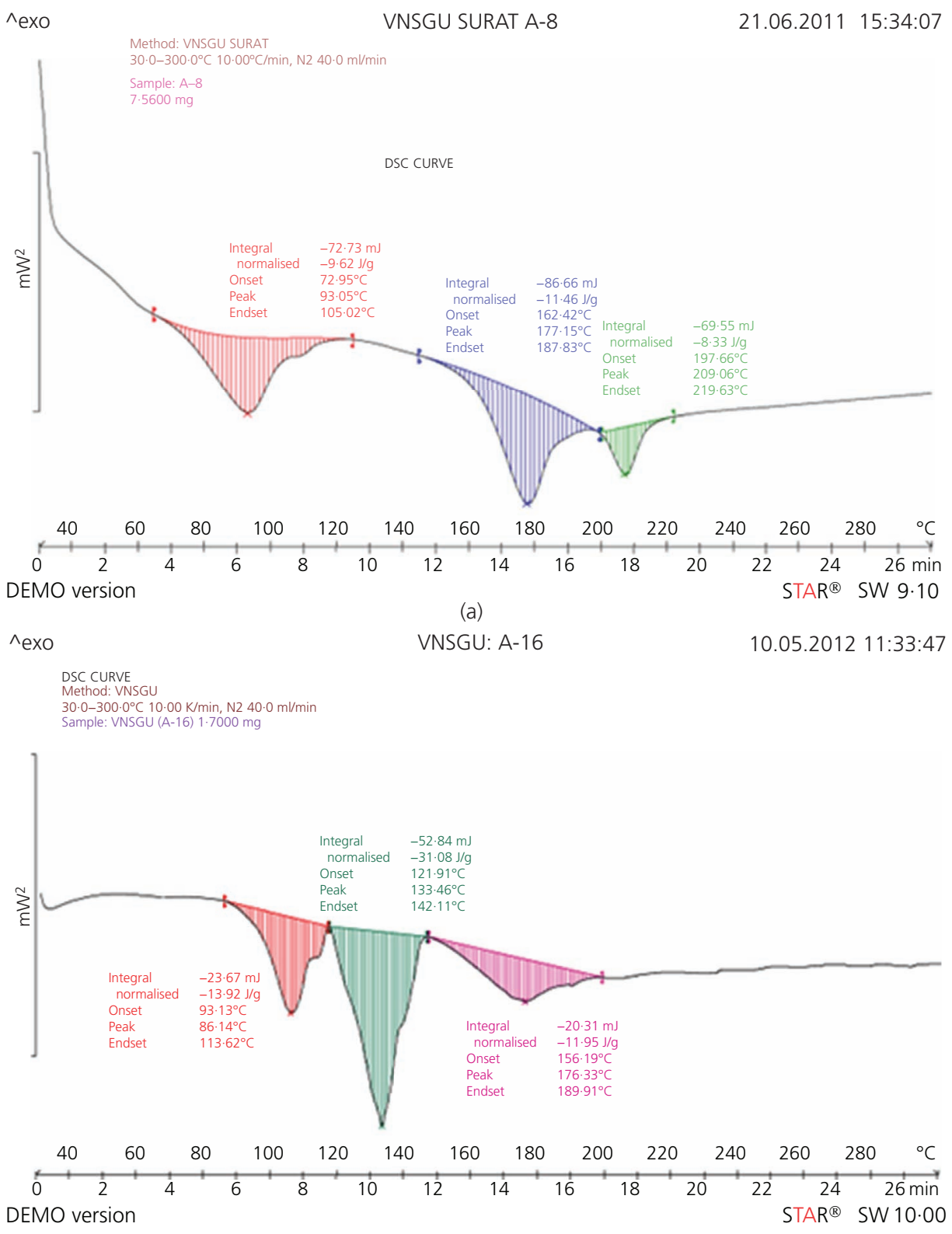

(b)

Figure 8. DSC thermograms of different compounds: (a) $A_{8}$, (b) $A_{16}$, (c) $B_{8}$ and (d) $B_{16}$ (continued on next page)

monotropic smectic A mesophase. It has been observed that the $\mathrm{C}_{12}$ compound of series $\mathrm{B}$ was fully monotropic in nature. A similar trend in transition temperatures was observed in 4- $n$ alkylphenyl-2'-choloro-4-(6- $n$-alkyl-2-naphthoyloxy)benzoates by Coates and Gray. ${ }^{35}$ The plot of transition temperature against the number of carbon atoms in the alkoxy chain (Figure 7(b)) exhibits a decreasing tendency in the $\mathrm{Cr}-\mathrm{N}, \mathrm{N}-\mathrm{I}, \mathrm{Sm}-\mathrm{N}$ and $\mathrm{Cr}-\mathrm{Sm}$ transition temperatures, and no odd-even effect could be seen in the transition temperature.

Series A and series B differ only in their terminal groups. Series $\mathrm{A}$ and $\mathrm{B}$ consist of $-\mathrm{Cl}$ and $-\mathrm{NO}_{2}$ terminal groups, respectively, and the alkoxy chain length of 6-alkoxy-2-naphthoic acid was varied. It has been observed that the transition temperature of series $\mathrm{B}$ is higher than that of series A. This may be attributed to the more polar nature of the $-\mathrm{NO}_{2}$ group, giving series $\mathrm{B}$ higher stability and higher temperature than that of the less polar $-\mathrm{Cl}$ terminal group.

The transition temperatures of copper metallomesogens of series $\mathrm{MC}$ and MD are given in Tables 3 and 4. The brown paramagnetic complexes $\mathrm{MC}_{16}$ and $\mathrm{MC}_{18}$ were shown to have a liquid crystalline structure. The complex $\mathrm{MC}_{16}\left(\mathrm{R}=-\mathrm{C}_{16} \mathrm{H}_{33}\right)$ showed a transition to a liquid crystalline phase at temperatures in 


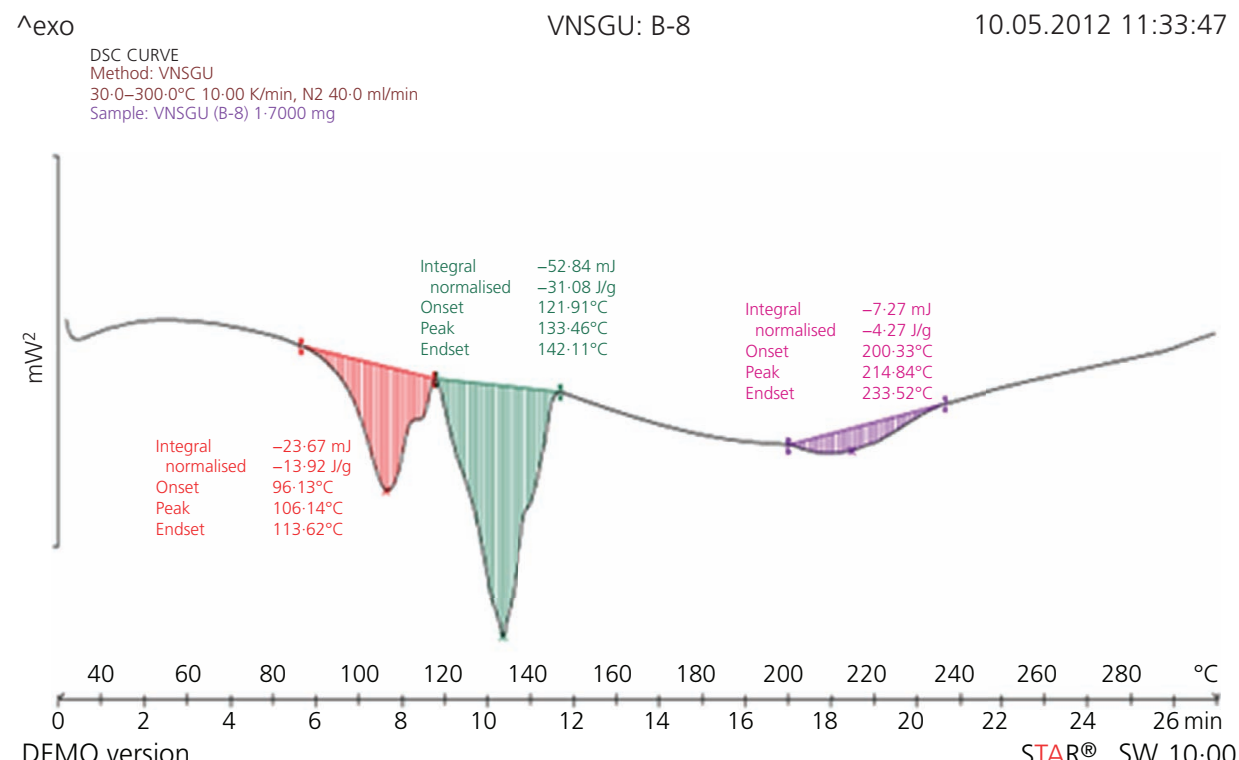

(c)

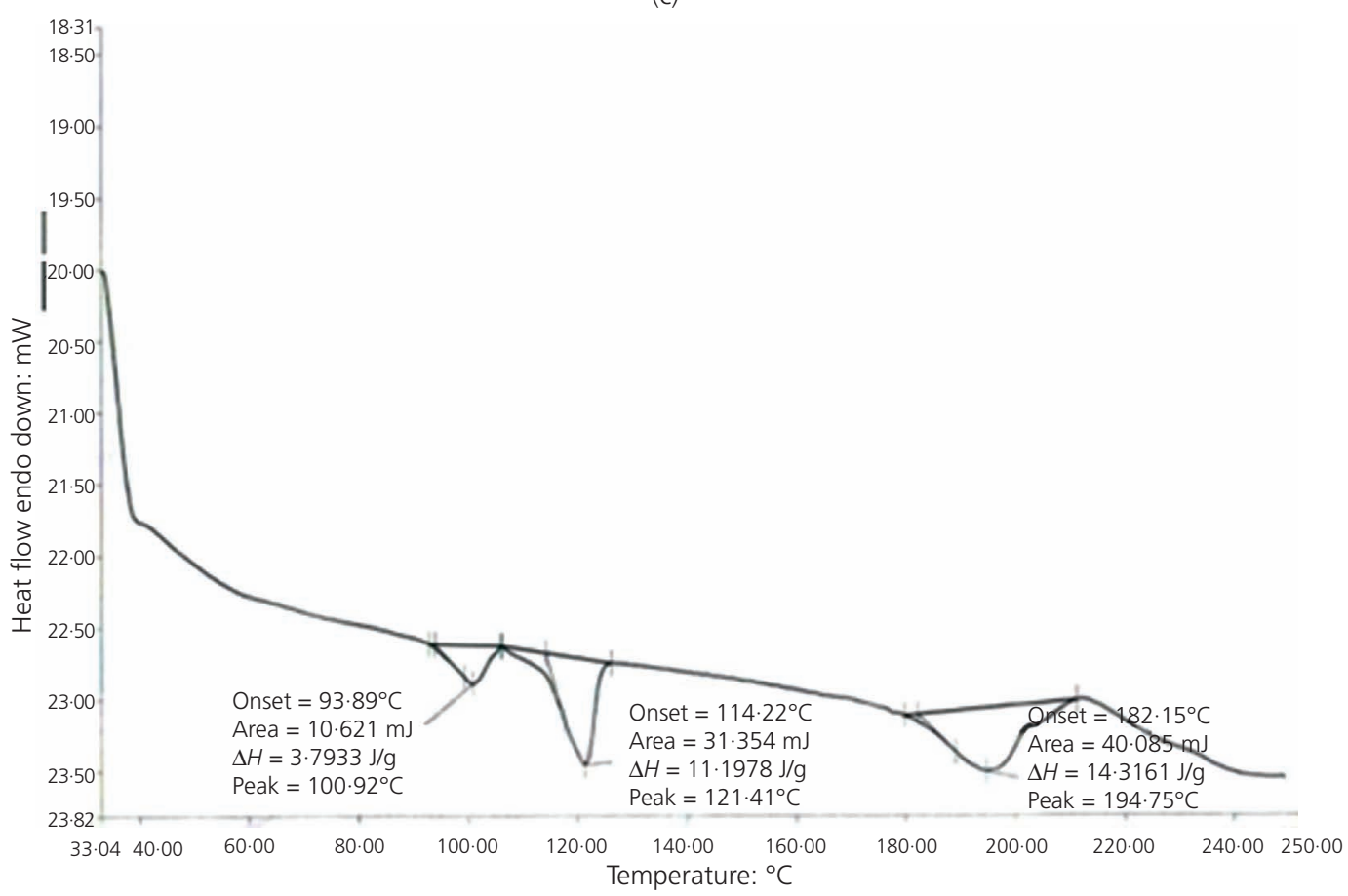

(d)

Figure 8. Continued

the range of $138-139^{\circ} \mathrm{C}$. It exhibits the schlieren texture of the nematic phase. The $\mathrm{MC}_{18}\left(\mathrm{R}=-\mathrm{C}_{18} \mathrm{H}_{37}\right)$ analogue showed a parallel behaviour. Similarly, $\mathrm{MD}_{16}$ and $\mathrm{MD}_{18}\left(\mathrm{R}=-\mathrm{C}_{16} \mathrm{H}_{33}\right.$ and $-\mathrm{C}_{18} \mathrm{H}_{37}$ ), both paramagnetic complexes, showed transition to a LC phase at 127 and $132^{\circ} \mathrm{C}$, respectively, showing the threaded texture of the nematic phase.

The DSC thermograms of series $\mathrm{A}$ and series $\mathrm{B}$ compounds $\mathrm{A}_{8}$ and $\mathrm{B}_{8}\left(\mathrm{R}={ }_{-} \mathrm{C}_{8} \mathrm{H}_{17}\right)$ and $\mathrm{A}_{16}$ and $\mathrm{B}_{16}\left(\mathrm{R}=-\mathrm{C}_{16} \mathrm{H}_{33}\right)$ are shown in Figures 8(a)-8(d). The thermograms of compounds $A_{8}$ and $A_{16}$ show three phase transition peaks at $93 \cdot 05,177 \cdot 15$ and $209 \cdot 66$ and $86.14,133.46$ and $176.33^{\circ} \mathrm{C}$, respectively. Similarly, the thermograms of compounds $\mathrm{B}_{8}$ and $\mathrm{B}_{16}$ also show three phase transition peaks at $106 \cdot 14,133.45$ and $214 \cdot 84$ and $100 \cdot 92$, 121.41 and $194.75^{\circ} \mathrm{C}$, respectively. These temperatures were exactly equivalent to the temperature observed by polarising optical microscopy (POM) corresponding to smectic A, nematic and isotropic transition temperatures. 
Table 5. Transition temperatures and DSC data of series A, B, MC and MD

\begin{tabular}{|c|c|c|c|c|c|}
\hline Series & Code & Transition & $\begin{array}{l}\text { Peak temp. } \\
\text { (microscopic } \\
\text { temp.): }{ }^{\circ} \mathrm{C}\end{array}$ & $\begin{array}{l}\Delta H: \\
J / g\end{array}$ & $\begin{array}{c}\Delta S: \\
J /(g ~ K)\end{array}$ \\
\hline \multirow[t]{6}{*}{ A } & \multirow[t]{3}{*}{$A_{8}$} & $\mathrm{Cr}-\mathrm{Sm}$ & 93.05 (93) & $9 \cdot 62$ & 0.0262 \\
\hline & & $\mathrm{Sm}-\mathrm{N}$ & $177 \cdot 15$ (177) & $11 \cdot 46$ & 0.0254 \\
\hline & & $\mathrm{N}-\mathrm{I}$ & $209 \cdot 06$ (209) & 8.33 & 0.0172 \\
\hline & \multirow[t]{3}{*}{$A_{16}$} & $\mathrm{Cr}-\mathrm{Sm}$ & $86 \cdot 14(86)$ & 13.92 & 0.0367 \\
\hline & & $\mathrm{Sm}-\mathrm{N}$ & 133.46 (133) & 31.08 & 0.0764 \\
\hline & & $\mathrm{N}-\mathrm{I}$ & $176 \cdot 33(176)$ & 11.95 & 0.0265 \\
\hline \multirow[t]{6}{*}{ B } & \multirow{3}{*}{$\mathrm{B}_{8}$} & $\mathrm{Cr}-\mathrm{Sm}$ & $106 \cdot 14(106)$ & 13.92 & 0.0367 \\
\hline & & $\mathrm{Sm}-\mathrm{N}$ & $133.46(133)$ & 31.08 & 0.0764 \\
\hline & & $\mathrm{N}-\mathrm{I}$ & $214.84(215)$ & $4 \cdot 27$ & 0.0087 \\
\hline & \multirow[t]{3}{*}{$B_{16}$} & $\mathrm{Cr}-\mathrm{Sm}$ & $100 \cdot 92(101)$ & $3 \cdot 79$ & 0.0375 \\
\hline & & $\mathrm{Sm}-\mathrm{N}$ & $121 \cdot 41(122)$ & $11 \cdot 19$ & 0.0921 \\
\hline & & $\mathrm{N}-\mathrm{I}$ & $194 \cdot 75$ (195) & $14 \cdot 31$ & 0.0734 \\
\hline \multirow[t]{2}{*}{$\mathrm{MC}$} & \multirow[t]{2}{*}{$M C_{18}$} & $\mathrm{Cr}-\mathrm{N}$ & $141.66(142)$ & $12 \cdot 18$ & 0.0859 \\
\hline & & $\mathrm{N}-\mathrm{I}$ & 204·57 (205) & $3 \cdot 51$ & 0.0171 \\
\hline \multirow[t]{2}{*}{ MD } & \multirow[t]{2}{*}{$M D_{18}$} & $\mathrm{Cr}-\mathrm{N}$ & 131.95 (132) & 4.08 & 0.0100 \\
\hline & & $\mathrm{N}-\mathrm{I}$ & $185 \cdot 20(185)$ & $14 \cdot 88$ & 0.0324 \\
\hline
\end{tabular}

temp., temperature; $\Delta H$, enthalpy; $\Delta S$, entropy

A comparison of the transition temperatures obtained by POM and DSC thermogram data is given in Table 5. It was observed that the transition temperatures were almost the same.

The DSC thermograms of copper LC complexes $\mathrm{MC}_{18}$ and $\mathrm{MD}_{18}$ $\left(\mathrm{R}=-\mathrm{C}_{18} \mathrm{H}_{37}\right.$ ), given in Figures 9(a) and 9(b), exhibit two phase transition peaks at 141.66 and 204.57 and 131.95 and $185 \cdot 2{ }^{\circ} \mathrm{C}$, respectively. It could be seen that after complex formation, the compound became more rigid and showed two transition peaks. The ligand molecules $\mathrm{MC}_{18}$ and $\mathrm{MD}_{18}$ showed three phase transitions. The authors observed that the isotropic phase, in the case of a complex compound, was not found, but it forms a glassy product as observed in early studies. ${ }^{36}$

The $\mathrm{MC}_{18}$ and $\mathrm{MD}_{18}\left(\mathrm{R}=-\mathrm{C}_{18} \mathrm{H}_{37}\right)$ copper $\mathrm{LC}$ complexes were subjected to electron paramagnetic resonance studies. The electron spin resonance spectra for the 1:1 chloroform + toluene $\left(\mathrm{C}_{6} \mathrm{H}_{5} \mathrm{CH}_{3}\right)$ frozen solution gave, respectively, $g_{\|}=2 \cdot 09, g_{\perp}=$ 2.035, $A_{\|}=15 \cdot 4$ (copper-63 $\left({ }^{63} \mathrm{Cu}\right)$ ) and $A_{\perp}=4 \cdot 0$ (copper-63); $|g|=2 \cdot 08$; and $|A|=7 \cdot 8$ and $g_{\|}=2 \cdot 098, g_{\perp}=2 \cdot 035, A_{\|}=15 \cdot 5$ (copper-63) and $A_{\perp}=4 \cdot 1$ (copper-63); $|g|=2 \cdot 082$; and $|A|=7 \cdot 9$ $\left(A \times 10^{-3} \mathrm{C} / \mathrm{m}\right)$.

The magnetic moment $\left(\mu_{\mathrm{eff}}\right)$, determined by the Faraday method, at room temperature of both copper (II) LC complexes was in the range of $1.78-1.82 \mu_{\mathrm{B}}$, indicating one unpaired electron present in the complexes; no other interaction was present, and the copper (II) LC complexes were mononuclear and non-electrolytic compounds.

The texture of compounds $\mathrm{A}_{8}, \mathrm{~A}_{16}, \mathrm{~B}_{8}, \mathrm{~B}_{16}, \mathrm{MC}_{18}$ and $\mathrm{MD}_{18}$ obtained from the heating/cooling of the compound in the POM is shown in Figure 10.

\section{Conclusion}

Two homologous series containing fused rings were synthesised and characterised. The thermal stability of series B, which contains a terminal $-\mathrm{NO}_{2}$ group, was higher than that of series $\mathrm{A}$, which contains a terminal $-\mathrm{Cl}$ group. Both series exhibited liquid crystalline properties. Both showed an enantiometric nematic phase, while higher homologues showed an enantiotropic smectic A phase. The copper complexes of series A and B ligands were also synthesised and showed a liquid crystalline threaded nematic phase. The copper (II) LC compounds were paramagnetic and non-electrolytic in nature.
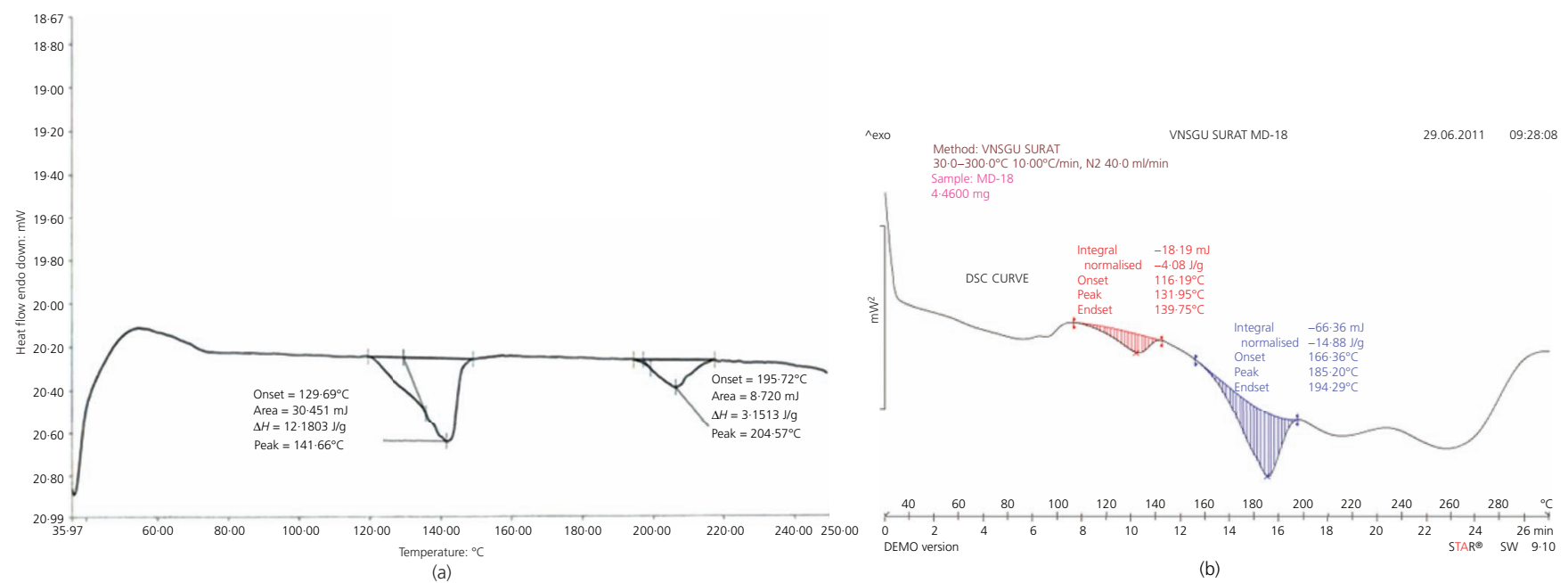

Figure 9. DSC thermograms of metallomesogens (a) $M C_{18}$ and (b) $M D_{18}$ 
Emerging Materials Research Volume 6 Issue EMR2
Calamitic liquid crystals involving fused

ring and their metallomesogens

Thaker, Limbachiya, Patel and Patel

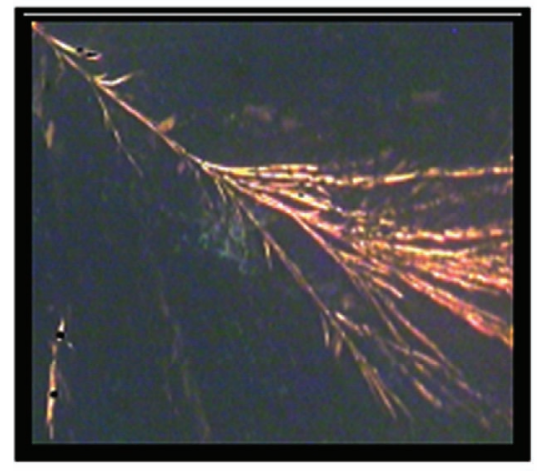

(a)

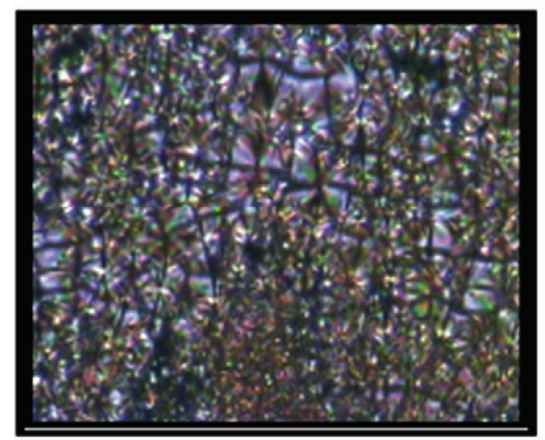

(c)

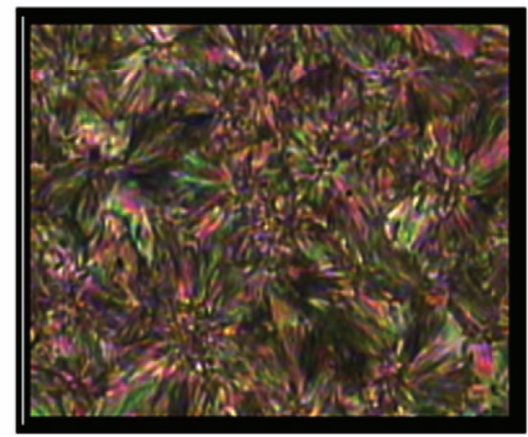

(e)

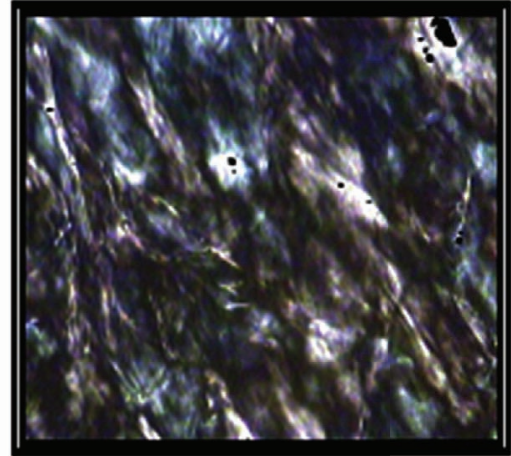

(b)

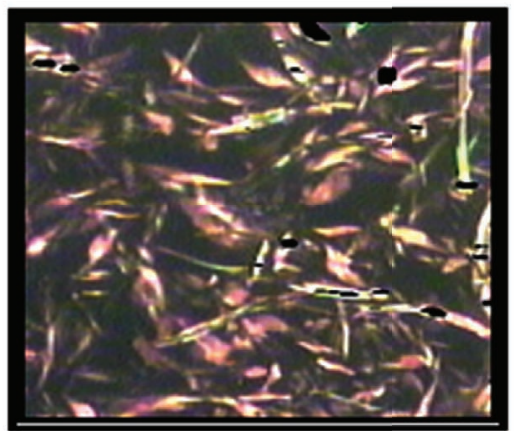

(d)

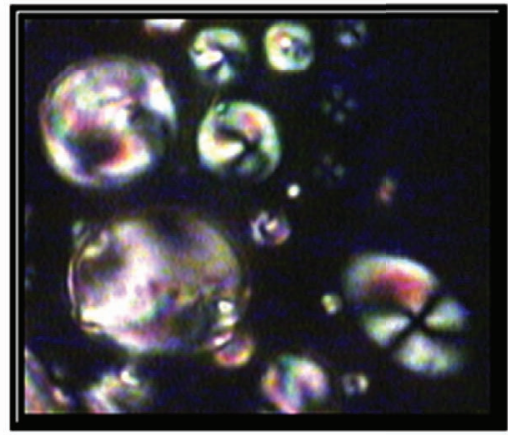

(f)

Figure 10. Optical texture obtained from POM on heating/cooling the compound: (a) nematic (schlieren-like) phase observed on cooling at $133^{\circ} \mathrm{C}\left(A_{16}\right)$, (b) smectic $A$ phase obtained on cooling at $93^{\circ} \mathrm{C}\left(A_{8}\right)$, (c) smectic $A$ (fan-shaped) phase exhibited on cooling at $106^{\circ} \mathrm{C}\left(B_{8}\right)$, (d) smectic A phase observed on cooling at $100^{\circ} \mathrm{C}\left(\mathrm{B}_{16}\right)$, (e) nematic (schlieren-like) phase observed on cooling at $142^{\circ} \mathrm{C}\left(\mathrm{MC}_{18}\right)$ and (f) nematic droplets observed on cooling at $131^{\circ} \mathrm{C}\left(\mathrm{MD}_{18}\right)$

\section{REFERENCES}

1. Matsumoto S, Kurihara T, Kubodera K and Kaino T (1990) Thirdorder nonlinear optical properties of dye-attached polymers. Molecular Crystals and Liquid Crystals 182A: 115-123.

2. Andre JM and Dellhalle J (1991) Quantum chemistry and molecular engineering of oligomeric and polymeric materials for optoelectronics. Chemical Reviews 91(5): 843-865.

3. Ulrich DR (1987) Multifunctional macromolecular ultrastructures: Introductory Comments Speciality Polymers '86. Polymer 28(4): 533-542.

4. Prasad PN (1991) Polymeric materials for non-linear optics and photonics. Polymer 32(4): 1746-1751.
5. Economy J (1990) Advanced materials: trends and possibilities in liquid crystalline polymers. Angewandte Chemie International Edition 29(11): 1256-1261.

6. Kozlovsky MV, Shibaev VP, Stakhanov Al, Weyrauch J and Hasse W (1998) A new approach to photorecording based on hindering a phase transition in photochromic chiral liquid crystalline polymers. Liquid Crystals 24(5): 759-767.

7. Ruslim C and Ichimura K (1998) Z-isomers of azobenzenes highly compatible with liquid crystals. Chemistry Letters 27(8): 789-790.

8. Ikada T and Tsutsumi O (1995) Optical switching and image storage by means of azobenzene liquid-crystal films. Science 268(5219): 1873-1875. 
9. Asaki T, Ikada T and Ichimura K (1994) Photochemical control of properties of ferroelectric liquid crystals: photochemical flip of polarization. Journal of the American Chemical Society 116(2): $625-628$.

10. Anderle K and Wendroff J (1994) Holographic recording, using liquid crystalline side chain polymers. Molecular Crystals and Liquid Crystals 243: 51-75.

11. Hermann DS, Rudquist $P$, Ichimura K et al. (1997) Flexoelectric polarization changes induced by light in a nematic liquid crystal. Physical Review E 55: 2857-2860.

12. Bauman D (1988) The study of the guest effect on the nematic phase stabilization. Molecular Crystals and Liquid Crystals 159: 197-218.

13. Zollinger H (1991) Color Chemistry. Wiley-VCH, Weinheim, Germany.

14. Gregory P (1991) High-Technology Application of Organic Coloring. Plenum Press, New York, NY, USA.

15. Umanskii B, Prudnikova E and Torgova S (1999) Designing a black mixture by dichroic dyes for liquid crystal devices. Molecular Crystals and Liquid Crystals 332: 27-36.

16. Gray GW (1979) Liquid crystal and moleclar structure - nematics and cholesterics. In The Molecular Physics of Liquid Crystals (Luckhurst GR and Gray GW (eds)). Academic Press, London, UK, p. 1.

17. Kobmehl G and Hoppe FD (1993) Liquid crystalline compounds in the thiophene series: VIII. synthesis and characterization of liquid crystalline vinylenes with thiophene moieties and carbaldehyde groups. Liquid Crystals 15(3): 383-393.

18. Sierra T, Serrano JL, Rose MB, Ezcurra A and Zubia J (1992) Synthesis and study of new $\alpha$-haloacid ferroelectric liquid crystal derivatives: MM2 approach to the molecular structure-ferroelectric activity relationship. Journal of the American Chemical Society 114(26): 7645-7651.

19. Lauk U, Scrabol P and Zollinger H (1983) Mesomorphic properties of some 6- $n$-alkyl-2-(4'-cyanophenyl)naphthalenes: preliminary communication. Helvetica Chimica Acta 66(5): 1574-1575.

20. Donnio B, Guillon D, Deschenaux R and Bruce DW (2003) Metallomesogens. In Comprehensive Coordination Chemistry II (McCleverty JA and Meyer TJ (eds)). Elsevier, Oxford, UK, vol. 7, pp. 357-627.

21. Giroud-Godquin AM and Maitlis PM (1991) Metallomesogens: metal complexes in organized fluid phases. Angewandte Chemie International Edition 30(4): 375-402.

22. Hoshino N (1998) Liquid crystal properties of metal-salicylaldimine complexes: chemical modifications towards lower symmetry. Coordination Chemistry Reviews 174: 77-108.
23. Wang CH, Wang YJ, Hu HM, Lee GH and Lai CK (2008) Novel metallomesogens derived from heterocyclic benzoxazoles. Tetrahedron 64(22): 4939-4948.

24. Gurol I and Ahsen V (2005) Synthesis, mesomorphism, and spectroscopic characterization of new Schiff bases and their $\mathrm{Cu}(\mathrm{II})$, Pd(II) complexes. Molecular Crystals and Liquid Crystals 442: 103-118.

25. Glebowska A, Przybylski P, Winck M et al. (2009) Fluorinated metallomesogens-lamellar versus columnar phase formation. Journal of Materials Chemistry 19(10): 1395-1398.

26. Barbera J, Gimenez R, Gimeno N et al. (2003) Bis(salicylaldiminate) copper(II) and palladium(II) complexes: towards columnar mesophases. Liquid Crystals 30(6): 651-661.

27. Ilis M, Micutz M, Dumitrascu F et al. (2014) Enhancement of smectic $\mathrm{C}$ mesophase stability by using branched alkyl chains in the auxiliary ligands of luminescent Pt(II) and Pd(II) complexes. Polyhedron 69: 31-39.

28. Rezvani Z, Nejati K, Alizadeh E and Sammimi R (2010) Synthesis and liquid-crystalline properties of $N /, N^{\prime}$-di-(5-(4-alkoxyphenyl)azo)salicylidene-1,2-phenylene diiminato nickel(II) complexes. Molecular Crystals and Liquid Crystals 533: 16-26.

29. Bhattacharjee CR, Datta C, Das G and Mondal P (2012) Liquid crystalline dinuclear copper(II) complexes accessed from photoluminescent tridentate [ONO]-donor Schiff base ligands. Liquid Crystals 39(5): 639-646.

30. Benbayer C, Besbes SS, Grelet E and Derdour A (2013) Structure-property study of new [1,2,3]-triazole liquid crystalline derivatives. Liquid Crystals 40(11): 1520-1528.

31. Cray GW and Jones B (1953) The mesomorphic transition points of pn-alkoxy benzoic acids. A Correction Journal of the Chemical Society 4179-4180.

32. Jones B (1935) Apparent cases of liquid crystal formation in p-alkoxybenzoic acids. Journal of the Chemical Society 1874

33. Vora RA, Prajapati AK, Kevat JB and Raina KK (2011) Mesogenic properties and the effect of 1,2,4-trisubstituted on the central benzene nucleus of a three ring mesogens. Liquid Crystals 28: 983-989.

34. Hird M, Seed AJ, Toyne KJ et al. (1993) Synthesis, transition temperatures and optical anisotropy of some isothiocyanatosubstituted biphenyls. Journal of Materials Chemistry 3(8): 851-859.

35. Coates D and Gray GW (1978) Synthesis and liquid crystal properties of some 4-n-alkylphenyl $2^{\prime}$-chloro-4'-(6-n-alkyl-2-naphthoyloxy) benzoates. Molecular Crystals and Liquid Crystals 41(5): 119-124.

36. Abser MN, Belwood M, Holmes MC and McCabe RW (1993) Aroylhydrazinatonickel(II) and copper(II) complexes; a new class of metallomesogens. Journal of the Chemical Society, Chemical Communications 13: 1062-1063.

\section{How can you contribute?}

To discuss this paper, please submit up to 500 words to the journal office at journal@ice.org.uk. Your contribution will be forwarded to the author(s) for a reply and, if considered appropriate by the editor-in-chief, it will be published as a discussion in a future issue of the journal.

ICE Science journals rely entirely on contributions from the field of materials science and engineering. Information about how to submit your paper online is available at www.icevirtuallibrary.com/page/authors, where you will also find detailed author guidelines. 